\title{
La selección y priorización de casos en la Jurisdicción Especial para la Paz
}

\author{
Selection and Prioritization of Cases in the Special Jurisdiction for Peace
}

\author{
Nelson Camilo Sánchez León ${ }^{\mathrm{a}}$ \\ Universidad de Virginia School of Law, Estados Unidos \\ csanchez@law.virginia.edu \\ ORCID: https://orcid.org/0000-0002-6927-3889 \\ Alejandro Jiménez Ospina \\ Centro de Estudios de Derecho, Justicia y Sociedad \\ (Dejusticia), Colombia \\ ORCID: https://orcid.org/0000-0001-8944-6751
}

DOI: https://doi.org/10.11144/Javeriana.vj69.spcj

Fecha de recepción: 07 Octubre 2019

Fecha de aprobación: 29 Noviembre 2019

Fecha de publicación: 30 Junio 2020

\section{Resumen:}

El objetivo de este artículo es analizar el estado de la discusión e implementación en Colombia de dos herramientas de racionalización para la Jurisdicción Especial para la Paz (en adelante JEP): la priorización y la selección de casos. El artículo analiza los desarrollos políticos y normativos a la fecha y concluye que ambos instrumentos, especialmente el de selección, fueron incluidos genérica y vagamente en el Acuerdo de Paz y que su desarrollo normativo ha sido paulatino y accidentado. En consecuencia, la JEP no cuenta con un marco concreto para desarrollar estas herramientas. Por ello, en la sección final, el artículo presenta una propuesta escalonada de aplicación de las herramientas que tiene un doble fin. Por un lado, operacionalizar las herramientas; por el otro, asegurar que estas respetan los estándares constitucionales e internacionales de investigación, juzgamiento y sanción de graves violaciones a derechos humanos.

Palabras clave: selección, priorización, acción penal, graves violaciones a derechos humanos, crímenes internacionales graves, Jurisdicción Especial para la Paz, Proceso de Paz Colombia.

\section{Abstract:}

This article studies the process of implementation of case selection and prioritization strategies carried out by the Colombian Special Jurisdiction for Peace (SJP). The article first tracks the history of the discussion on the application of these mechanisms in the Colombian Peace Accord. Due to international and domestic factors, the Peace Accord only included a vague and contradictory language on the matter. Moreover, further regulations approved by Congress, and case law decided by the Colombian Constitutional Court, have not clarified the powers and the criteria the SPJ should use to select cases. Against this backdrop, the paper presents a novel framework that the SPJ could use to implement an effective case selection strategy that respects the internationally recognized rights of the victims of gross human rights violations.

Keywords: case selection, prioritization, gross human rights violations, core international crimes, Special Jurisdiction for Peace, Colombian Peace Process.

\section{Introducción}

La sociedad colombiana enfrenta múltiples retos en su intento de lograr una transición completa y sostenible del conflicto a la paz. El cumplimiento de los distintos puntos del Acuerdo Final para la Terminación del Conflicto y la Construcción de una Paz Estable y Duradera (en adelante AFP) ${ }^{[1]}$ requiere transformaciones sociales, institucionales y legales de una gran dimensión. Dentro de estos desafíos, uno de los aspectos sobre

Notas de autor

${ }^{a}$ Autor de correspondencia. Correo electrónico: csanchez@law.virginia.edu 
los que más han girado las discusiones políticas ha sido aquel de la forma de asegurar un reproche penal a quienes cometieron graves violaciones a los derechos humanos durante el conflicto armado ${ }^{[2]}$.

Las discusiones han partido de la construcción nacional e internacional del derecho de las víctimas a la justicia y como una garantía de no repetición y prevención de la impunidad ${ }^{[3]}$. Si bien la consolidación de este derecho en la cultura judicial colombiana ha sido un notable avance, en la práctica existen todavía muchas dudas sobre cuáles son los mejores dispositivos institucionales para, dentro del específico contexto colombiano, hacer real dicho principio ${ }^{[4]}$. Uno de los aspectos que lideran esta discusión es el de cómo crear un sistema de rendición de cuentas penal que logre lidiar con un número tan elevado de combatientes y hechos delictivos. La realidad colombiana es, a simple vista, abrumadora para cualquier sistema penal: más de ocho millones de víctimas según el Registro Único de Víctimas, por lo menos tres grupos de organizaciones armadas, legales e ilegales, cometiendo delitos en el marco del conflicto, y procesos de negociación descoordinados o incluso paralelos, pero aislados ${ }^{[5]}$.

Evidentemente, Colombia no es el primer país que debe enfrentar retos como estos y tampoco es la primera vez que lo intenta. Experiencias anteriores (como la Argentina y sus históricos Juicios a la Junta de $1985^{[6]}$ ) han acudido a mecanismos para racionalizar la acción penal, con dos objetivos en mente: (i) permitir que se dé una negociación para terminar el conflicto armado y, (ii) cumplir en la mayor medida posible la obligación de investigar, juzgar y sancionar ${ }^{[7]}$. Las estrategias de priorización y selección han sido instrumentos primordiales que, tanto en la teoría como en la práctica, se han promovido para conciliar estos intereses.

Los conceptos de priorización y selección han estado muy presentes en las discusiones sobre marcos jurídicos de desmovilización y paz en la Colombia contemporánea ${ }^{[8]}$. Sin embargo, a diferencia de otras experiencias comparadas, la discusión colombiana se ha centrado en cómo lograr un proceso de selección y priorización jurídico, y no político, en un órgano judicial doméstico no internacionalizado. En este aspecto hay muy pocos precedentes pues han sido los vencedores en la contienda militar los que han elegido a un grupo representativo de individuos para ser juzgados (como en el caso de los juicios de Nuremberg o Tokio ${ }^{[9]}$ ), o han sido las fuerzas democráticas en transiciones paradigmáticas que se han concentrado en la cúpula militar oficial que soportaba al régimen (como sucedió en el anotado caso argentino ${ }^{[10]}$ ). Lo que no ha sido común es que sea el propio sistema de justicia bajo criterios estrictamente jurídicos el encargado de realizar esta selección. Pareciera que el mismo caso colombiano da luces y presenta ejemplos, especialmente luego de la implementación del Marco Jurídico para la Paz y la estrategia de selección y priorización de casos de la Fiscalía General de la Nación.

El presente artículo analizará el estado de la discusión sobre selección y priorización en el actual proceso de judicialización de las atrocidades ocurridas en el conflicto colombiano. El argumento que defenderemos es el siguiente: los instrumentos de priorización y, sobre todo, selección, fueron incluidos de manera genérica y vaga en el texto del AFP. Esta falta de asertividad para la regulación de una herramienta trascendental para el proceso se debió a dos factores. Por un lado, a que en el momento en el que se dio la discusión, existía cierta reticencia de algunos organismos internacionales de derechos humanos a aceptar la selección por un temor a que se vulnerara, por esta vía, el derecho a la justicia de las víctimas. Esto impactó en la posición del gobierno, que buscó proponer lenguajes matizados de las facultades de priorización y selección, con el fin de no crear pronunciamientos adversos de la comunidad internacional. Por otro lado, la poca claridad sobre facultades y criterios de selección de casos se debió a una resistencia interna al tema de la selección y priorización por parte de las élites militares (guerrillas y fuerzas oficiales). Los procesos de regulación normativa y aplicación del AFP cargan, entonces, con la enorme tarea de darle contenido concreto y aplicabilidad a estos principios. Sin embargo, las normas aprobadas por el Congreso ${ }^{[11]}$ no llenan del todo los vacíos existentes. Por ello, como suele ser común en Colombia, las cortes tendrán la última palabra sobre el contenido y alcance de estos principios. Por ahora, tanto la Corte Constitucional como la JEP han iniciado el intrincado proceso de crear contenido. Sin embargo, hasta la fecha, la Corte Constitucional se ha limitado a reafirmar la 
constitucionalidad de las figuras $^{[12]}$-algo que es un importante avance-. Sin embargo, probablemente para evitar quedar en el medio de debates políticos, la Corte ha dejado a cargo de la JEP la difícil y controversial tarea de tomar decisiones prácticas sobre criterios de aplicación. En consecuencia, la selección sigue siendo un tema con un alto grado de indeterminación jurídica y que genera una alta polarización política.

Para defender esta tesis, dividiremos el artículo de la siguiente manera: en primera medida, haremos un breve recuento de la historia de estos mecanismos en Colombia. Luego se hará una revisión de lo dispuesto en el AFP respecto de la selección y priorización de casos en la JEP. Se expondrá la forma en que esa ambigüedad ha sido abordada por la Corte Constitucional y el Congreso de la República, para terminar con un acercamiento al trabajo de la propia JEP. De manera que el lector pueda identificar los desarrollos actuales y las necesidades vigentes y tener a su disposición un bosquejo del escenario actual. Igualmente, quien lea podrá considerar las oportunidades de avance y la forma en que estas podrían ser gestionadas desde una estrategia que tenga en cuenta tanto los derechos de las víctimas y los objetivos de la transición, como las limitaciones existentes en términos de marco normativo, recursos y capacidades institucionales.

\section{Breve recuento de la historia de la priorización y selección como mecanismo de racionalización de la acción penal en Colombia}

En los últimos años se ha consolidado en el marco del derecho internacional de los derechos humanos el principio jurídico conocido como deber estatal de investigar, juzgar y sancionar las violaciones graves a los derechos humanos ${ }^{[13]}$. No obstante, en situaciones de violencia masiva suele ser desafiante determinar el contenido y alcance de este deber ${ }^{[14]}$. De hecho, si en muchas ocasiones es un deber exigente de cumplir para casos aislados de violencia o criminalidad ordinaria, en contextos de violaciones masivas existen muchas dudas sobre la capacidad que tendría un Estado que no ha logrado controlar su seguridad de manera adecuada, para llevar a cabo de manera eficiente y efectiva la investigación, persecución, sanción y castigo de un número masivo de perpetradores responsables de un número exponencialmente mayor de crímenes ${ }^{[15]}$.

Dos de las principales estrategias para ello, a partir de la concentración de la acción penal, fue lo que en la actualidad se conoce como selección y priorización. Como sostiene Orozco, "seleccionar es decidir qué se toma y qué se descarta, qué se persigue y qué no se persigue. Priorizar, por su parte, es decidir qué se persigue primero y qué se persigue después" ${ }^{[16]}$. La selección no es nueva ni para el derecho penal, ni para la justicia transicional. Por un lado, todos los sistemas penales, incluso en contextos de alta normalidad constitucional, tienen una imposibilidad fáctica de tramitar todos los delitos que ocurren. Esto vale para sistemas ordinarios o extraordinarios, nacionales o internacionales, por eso la selección siempre está presente: o planeada, o de hecho (de manera caprichosa, involuntaria y descontrolada). Por este motivo, las estrategias de política criminal moderna prefieren, en lugar de mantener el deber de castigar como una regla rígida que lleve a ocultar la criminalidad y con ello produzca el descrédito de la justicia, racionalizar la intervención estatal para decidir de manera democrática cuáles deben ser las prioridades en materia penal ${ }^{[17]}$. Por otro lado, la selección es también un principio connatural a la justicia transicional, pues dada la masividad de hechos y perpetradores, así como de tareas por encarar y necesidades públicas, es necesario racionalizar la acción del Estado y la sociedad conforme a unos acuerdos básicos fundamentales ${ }^{[18]}$.

En esta sección presentaremos cuáles eran los debates que se suscitaban en la comunidad de internacional de derechos humanos y derecho penal internacional en la época en la que en Colombia se discutían las opciones de estrategia de persecución de los casos del conflicto armado en el nivel constitucional. Con este recuento mostraremos cómo estas discusiones marcaron el contenido del AFP y la implementación normativa que siguió. Allí el punto es la forma en que fue abordada la necesidad de racionalizar la acción penal para dar un 
cierre jurídico al conflicto armado, garantizar seguridad jurídica a los excombatientes y satisfacer los derechos de las víctimas, especialmente a la verdad y la justicia.

\section{La obligación de investigar, juzgar y sancionar y su interacción con la justicia transicional y la necesidad de racionalizar la acción penal}

Desde el inicio de procesos de juzgamiento posguerra, como es el caso de los juicios de Nuremberg y Tokio, se recurrió a estrategias de concentración de la acción penal ${ }^{[19]}$. Con el fin de enfocar los juicios penales en las estructuras que posibilitaron las atrocidades masivas, los procesos internacionales de justicia transicional han hecho uso recurrente de la categoría de máximo responsable. Por ejemplo, los tribunales internacionales adhoc históricamente limitaron la persecución penal a aquellos que encuadran en esta noción ${ }^{[20]}$. Algo similar han hecho tribunales nacionales que han enfrentado atrocidad masiva, como es el caso de Argentina y de Bosnia y Herzegovina ${ }^{[21]}$.

No obstante, en los últimos años y tras la consolidación del deber de investigar, juzgar y sancionar, ha existido un debate sobre la legalidad -desde el punto de vista del derecho internacional- de la aplicación de estos principios -especialmente el de selección-. Esta discusión, por supuesto, ha estado en el centro de los debates colombianos. Por ejemplo, si bien no existe aún una decisión de la CPI que aborde este tipo de cuestiones, durante el trámite del proceso de constitucionalidad del Marco Jurídico para la Paz en Colombia, la fiscal de la CPI envió a la Corte Constitucional dos cartas en las cuales expresaba algunas opiniones en relación con la política de selección de casos y responsables y con la posibilidad de suspender penas a los máximos responsables de crímenes atroces. En una de esas cartas ${ }^{[22]}$, la fiscal aclaró a la Corte Constitucional colombiana que la estrategia procesal de la Fiscalía de la CPI, que centra los esfuerzos de judicialización en los máximos responsables, no debía interpretarse como un precedente que autorizara a los Estados a adoptar una estrategia similar en un contexto doméstico ${ }^{[23]}$.

En su momento, esta interpretación de la obligación de investigar y juzgar de la Fiscalía de la CPI fue compartida por otras instancias. En el sistema interamericano, por ejemplo, en su informe sobre Colombia de 2013, la $\mathrm{CIDH}^{[24]}$ pareció dejar muy poco margen de maniobra para una negociación de paz al establecer que incluso un sistema de juzgamiento estructurado a partir de la investigación, juzgamiento y sanción efectiva solo de los máximos responsables de los crímenes más graves sería contrario al derecho a la justicia establecido en la Convención Americana sobre Derechos Humanos, pues permitía la renuncia de la acción penal frente a aquellos que no sean seleccionados.

Estas visiones maximalistas de la obligación de investigar y juzgar han unido a un importante sector de doctrinantes y practicantes que se preocupan por los resultados negativos para las negociaciones de paz que pudiera tener un estándar demasiado exigente de justicia ${ }^{[25]}$. Entre éstos se encuentra el grupo que impulsó las Pautas de Belfast sobre Amnistía y Responsabilidad, unos lineamientos que "ayudan a los estados a reconocer la función positiva de ciertas formas de amnistía para fomentar la política transicional y los objetivos de

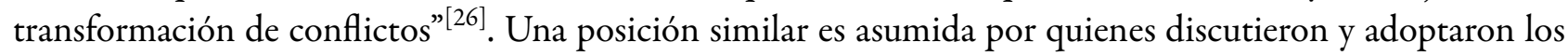
Principios de Chicago sobre justicia transicional ${ }^{[27]}$.

\section{El debate colombiano sobre racionalización de la acción penal}

La desmovilización de los grupos paramilitares a principios de la década anterior inició la discusión sobre el rol de la acción penal frente a las acciones del conflicto en el marco de procesos de paz y desmovilización voluntarios. Si bien el debate inició con un llamado por la amnistía general, prontamente la movilización de 
las víctimas impidió que se optara por esta salida ${ }^{[28]}$. El debate se decantó con la discusión parlamentaria que llevó a la adopción de la Ley de Justicia y Paz. Este modelo demostró sus limitaciones prontamente. En primer lugar, el sistema no fue lo suficientemente eficiente para procesar de manera rápida el número de casos que entraron a través de la propia solicitud de los excombatientes ${ }^{[29]}$. Por otro lado, la relación de combatiente/ caso no era una unidad de medida efectiva para el procesamiento por dos razones. Primero, al ser necesario el procesamiento de todos los hechos, aun cuando a un excombatiente específico se le condenara por uno o varios delitos, si no se le condenaba por todos los hechos se podía entender que ese crimen específico, estaba quedando impune y, por lo tanto, se incumplía con la obligación estatal de investigar y juzgar. Segundo, al no existir concentración en personas sino en delitos, todo aquel que hubiere participado en un delito no amnistiable, independientemente de su función en el crimen y su rango en la organización, debía ser juzgado por el sistema. Como consecuencia de esto, la meta del gobierno de seleccionar para procesamiento judicial solo la fracción de combatientes postulados a Justicia y Paz y proveer una amnistía (o medida similaral grupo más grande de excombatientes desmovilizados se hizo inalcanzable.

El gobierno y el Congreso decidieron entonces recurrir a un mecanismo de flexibilización del sistema mediante la introducción de la figura del principio de oportunidad ${ }^{[30]}$. Sin embargo, la Corte Constitucional ${ }^{[31]}$ cerró esta puerta y adoptó una posición muy estricta, que prácticamente hacía imposible una política de selección de casos (incluso para aquellos que no constituyeran graves violaciones a los derechos humanos). Frente a esta decisión -que fue considerada por el Gobierno del momento como una crisis del proceso de desmovilización, pues impedía la definición rápida de la situación jurídica de más de 15.000 desmovilizados-, Gobierno y Congreso trabajaron en una nueva alternativa con base en los lineamientos de la Corte. En esta nueva medida, que se adoptó mediante la Ley 1424 de 2010, todos los combatientes acudirían a un proceso penal (los postulados a partir del sistema de Justicia y Paz, mientras que el grupo mayoritario a un proceso mixto de confesión ante el Centro Nacional de Memoria Histórica y una posterior revisión judicial ante jueces ordinarios) y aquellos que no hubieren cometido crímenes atroces tendrían una sanción mediante la declaración de responsabilidad en la sentencia judicial, pero no estarían sujetos a penas de privación de la libertad. Así las cosas, la crisis se intentó solventar por la vía de la reducción de la pena, pero sin posibilidad de selección ${ }^{[32]}$.

Para entonces era claro que la tarea de juzgar individualmente cada caso y cada excombatiente era prácticamente imposible de lograr en un marco de tiempo menor a cien años ${ }^{[33]}$. Priorizar y seleccionar casos parecía la única opción posible para destrabar el sistema, pero la Corte Constitucional había dejado poco margen para hacerlo. Esta fue una de las razones por las cuales el gobierno Santos promovió la reforma constitucional que se conoce como el Marco Jurídico para la Paz. Allí se introdujeron de manera explícita en la Constitución las facultades para que la Fiscalía General de la Nación priorizara casos y para que, con base en una ley estatutaria, el Congreso señalara criterios para la selección de casos, incluso cuando estos se refieran a graves violaciones a los derechos humanos o infracciones graves al derecho internacional humanitario ${ }^{[34]}$.

Defensores de la visión maximalista del deber de investigar llevaron el tema nuevamente ante la Corte Constitucional mediante una demanda de inconstitucionalidad de la reforma constitucional bajo la figura de la sustitución de la Constitución. Finalmente, la Corte avaló la reforma constitucional. Para hacerlo, buscó armonizar lo máximo posible la visión más tradicional del deber de investigar, juzgar y sancionar con la posibilidad de flexibilizar el sistema de investigación, imputación y sanción. El primer paso para esto fue diferenciar entre investigación e imputación. Según la Corte:

La concentración de la responsabilidad en los máximos responsables no implica que se dejen de investigar todos los delitos de lesa humanidad, genocidio y crímenes de guerra cometidos de manera sistemática, sino que permite que sean imputados solo a quienes cumplieron un rol esencial en su comisión ${ }^{[35]}$. 
Por tanto, la obligación del sistema de justicia es la investigación de las violaciones a partir de macroprocesos y se le permite concentrar la imputación en los máximos responsables. Por ende, al final de la investigación, a la hora de estructurar la imputación, se deben vincular estos hechos a los máximos responsables, con lo cual se estaría haciendo justicia así no todos los que hayan participado de los hechos estén siendo imputados. Así lo expresa la Corte cuando señala:

Toda grave violación a los Derechos Humanos y al Derecho Internacional Humanitario constitutiva de delito de lesa humanidad, genocidio o crimen de guerra cometido de manera sistemática debe ser vinculada a un máximo responsable. En este esquema ninguno de estos crímenes quedara\# en la impunidad, sino que todos tendrán que ser imputados a sus máximos responsables ${ }^{[36]}$.

Adicionalmente, la Corte aceptó la renuncia condicionada a la acción penal de aquellos participantes del delito que no sean considerados como máximos responsables como uno de los elementos necesarios de esta estrategia. Para ajustar esta figura a las obligaciones del Estado, la Corte dio unos lineamientos, entre ellos, señaló que

Los casos no seleccionados serán aquellos que incluyan una de tres categorías: (i) Personas que no siendo máximos responsables hayan participado en la comisión de delitos de lesa humanidad, genocidio o crímenes de guerra cometidos de manera sistemática. (ii) Personas que hayan cometido delitos que no sean considerados como crímenes de lesa humanidad, genocidio ni crímenes de guerra [...] (iii) Crímenes de guerra que no sean cometidos de manera sistemática es decir sin un nexo con el conflicto ${ }^{[37]}$.

Al tiempo que esto ocurría, la Fiscalía General de la Nación comenzó a diseñar e implementar la estrategia de selección y priorización de casos que aplicaría de ahí en adelante. Derivado de esto hay distintas lecciones aprendidas, que no son objeto de discusión en este artículo, pero que vale la pena revisar si lo que se quiere es reconstruir de forma completa la historia de estos mecanismos en Colombia. Luego se promovería una reforma a la Ley de Justicia y Paz, a través de la Ley 1592 de 2012, que pretendía, entre otras cosas, facilitar la implementación del modelo de selección y priorización dentro del proceso transicional.

Con el aval de la Corte, algunos miembros de la delegación del gobierno en la mesa de negociaciones de La Habana sintieron que el panorama de discusión de la fórmula de justicia se despejaba. Por un lado, la legitimidad de la Corte Constitucional podría llevar a una cierta apertura de las posiciones más maximalistas de los organismos internacionales, y, por el otro, la guerrilla podía tomar la sentencia como una invitación muy seductora para iniciar la negociación de un grado de justicia que no necesariamente llevara a la imputación penal de toda la tropa.

En cuanto a lo primero, si bien las previsiones se cumplieron, algo distinto ocurrió con la discusión de La Habana. Primero, las FARC consideraron que la reforma constitucional era una imposición unilateral del gobierno a la mesa por lo cual, sin importar su contenido, la rechazaban ${ }^{[38]}$. Segundo, si bien para los líderes de un ejército en negociación puede ser una buena noticia partir del hecho de que no toda la tropa será imputada, esta teoría de selección puede resultar poco atractiva por tres razones. La primera es obvia: el sistema requiere que sean los propios negociadores los que terminen rindiendo cuentas a la justicia, pues precisamente por su grado de dirección política y militar, serían los candidatos perfectos para llenar el rubro de "máximos responsables". Además, para un grupo armado que hace tránsito a partido político puede ser mejor un sistema en donde muchos rindan cuentas y no unos pocos, pues las responsabilidades se diluyen y los cuadros políticos no terminan con todo el estigma del conflicto. Un argumento complementario que se escuchó en el debate fue la garantía de ascendencia y liderazgo para la reinserción: si a los mandos de la guerrilla, por ejemplo, se les exige que respondan por el cumplimiento de su tropa de los compromisos de reincorporación, una concentración en la sanción de éstos minaría de manera simbólica y práctica su posibilidad de ejercer liderazgo para responder por este compromiso ${ }^{[39]}$. 


\section{La priorización y selección en el sistema de justicia transicional propuesto en el acuerdo final de paz}

Ese escenario de falta de certeza sobre la fórmula de justicia a adoptar en el marco de la negociación entre las FARC y el Gobierno Nacional llevó a una especie de estancamiento. Durante más de un año la mesa se centró en discutir el punto cinco de la agenda, relacionado con las víctimas del conflicto armado colombiano y sus derechos, sin llegar a acercamientos que permitieran adoptar mecanismos que cumplieran estándares internacionales y constitucionales en materia de derechos humanos, pero que al tiempo habilitaran el proceso de dejación de armas de los combatientes. Como ya se explicó, uno de los puntos neurálgicos de la discusión era la obligación de investigar, juzgar y sancionar los delitos cometidos por las distintas partes en la negociación.

Luego de más de cincuenta años de guerra, más de ocho millones de víctimas registradas y la certeza sobre la existencia efectiva de graves violaciones a derechos humanos y crímenes internacionales cometidos en el marco del conflicto, determinar la manera de investigar, juzgar y sancionar a quienes pudieran haber participado en estos delitos no era una tarea fácil. Especialmente luego de la experiencia del proceso de Justicia y Paz ${ }^{[40]}$, que fue diseñada sin mecanismo de selección y priorización y que luego tuvo que ser modificada al verificar el colapso del sistema ${ }^{[41]}$. El mecanismo que se utilizaría para hacer una rendición de cuentas judicial efectiva y respetuosa de los derechos de las víctimas pasaba por un reconocimiento concreto: que el Estado no tenía la capacidad de abordar todas las graves violaciones a derechos humanos y crímenes internacionales, ni hacer responsables a todos los perpetradores de los mismos, pero que de hecho tenía una obligación internacional y constitucional de intentarlo. Además, pretender hacerlo no solamente generaría falsas expectativas en las víctimas, sino que podría hacer imposible una paz negociada. Por lo que se hacía necesario acudir a una fórmula de racionalización de la acción penal que, aparentemente, no podía pasar por el Marco Jurídico para la Paz, dadas las dificultades que tenían las FARC con esta reforma constitucional.

Así, en la mesa se diseñó un nuevo modelo de justicia para la transición, cuyo núcleo es la JEP, basada en principios de justicia restaurativa y dialógica. El problema a abordar era entonces el alcance y enfoque del deber de investigar, juzgar y sancionar, así como la forma en que la JEP iba a encarar los múltiples repertorios de violencia y las violaciones a gran escala que ocurrieron dentro de su marco competencial.

La JEP, que es el componente de justicia dentro del el Sistema Integral de Verdad, Justicia, Reparación y No Repetición (en adelante SIVJRNR), fue diseñada como un sistema autocontenido, aplicable "a todos los que participaron de manera directa o indirecta en el conflicto armado" ${ }^{\text {[42] }}$. Con la salvedad que respecto de "los combatientes de los grupos armados al margen de la ley (...) solo se aplicará a quienes suscriban un acuerdo final de paz con el Gobierno Nacional" [43]. Asimismo, en relación con el marco temporal que abarca su competencia, se pactó que no tendría fecha de inicio, pero sí de finalización. Es decir, la competencia temporal de la JEP cubre todos los hechos relacionados con el conflicto armado ocurridos hasta antes del 1 de diciembre de 2016. Esto le deja un universo de hechos objeto de su competencia demasiado amplio, tanto desde el punto de vista de las circunstancias de tiempo, modo y lugar en que ocurrieron como de los autores y partícipes de los mismos. Para usar un ejemplo que puede dar luces sobre la dimensión de ese universo, según cifras oficiales, para el 2013 sólo para los delitos reconocidos por los postulados en el proceso de Justicia y Paz (Ley 975 de 2005) se calculaba que el sistema tardaría aproximadamente 99 años en procesar a todas las personas relacionadas. Y un cálculo similar que se hizo para quienes se sometieron por la vía de la Ley 1424 de 2010 arrojó un marco temporal de aproximadamente 526 años para procesarlas ${ }^{[44]}$.

Reconocer las dificultades y retos que planteaba un panorama como este llevó a diseñar un sistema sensible a los problemas de gestión judicial que pudieran derivar de un universo de casos de tal magnitud, como aparece en la figura 1 , y a un acuerdo en la mesa de negociaciones respecto a la fórmula de racionalización de la acción penal. En cuanto a la estructura, la idea inicial era generar un efecto embudo en la puerta de entrada de la JEP. 
La Sala de Reconocimiento de Verdad y Responsabilidad y de Determinación de los Hechos y Conductas (en adelante SRVR) sería la puerta de entrada, las diferentes fuentes de información para el trabajo de la JEP tendrían allí su repositorio y, desde ese punto, se repartirían los casos al interior del sistema ${ }^{[45]}$. Inicialmente, la SRVR debería remitir a la Sala de Amnistía e Indulto (en adelante SAI) y a la Sala de Definición de Situaciones Jurídicas (en adelante SDSJ) lo de su competencia y, posteriormente, determinaría la forma en que ciertos casos llegarían al Tribunal de Paz y la Unidad de Investigación y Acusación (en adelante UIA).

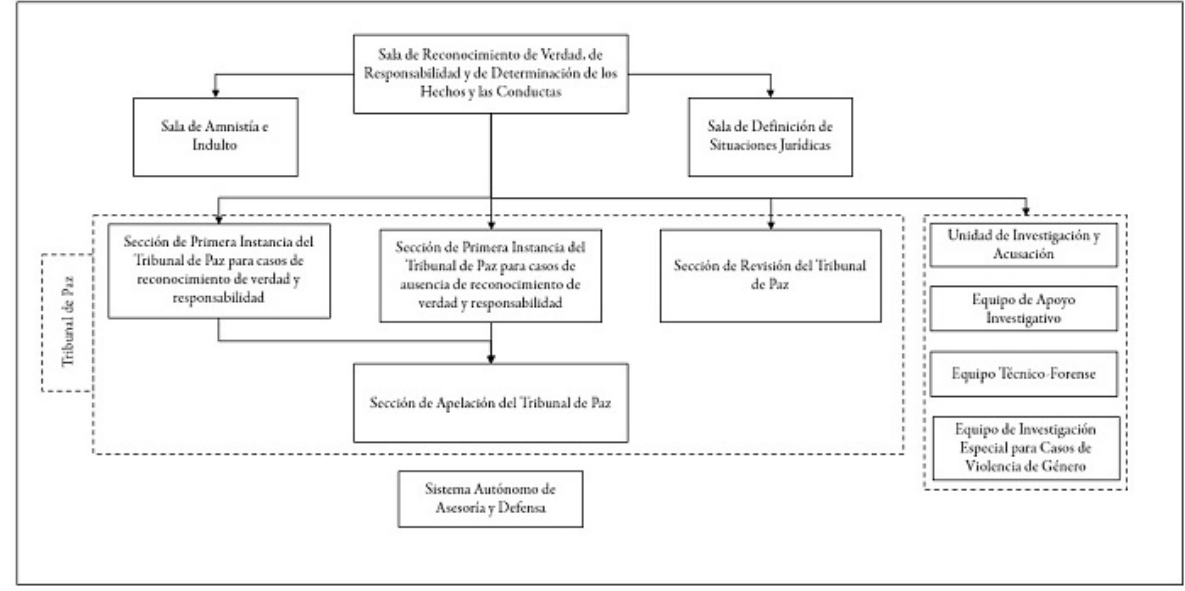

FIGURA 1.

Estructura básica de la JEP según el AFP

Fuente: elaboración propia

Mientras tanto, desde el punto de vista de la racionalización de la acción penal se tomaron dos decisiones que fueron desarrolladas ampliamente en el AFP y una menos clara y explícita: (i) se pactó explícitamente renunciar a perseguir los delitos menos graves y otorgar amnistías, indultos o tratamientos similares a quienes los cometieron; (ii) se determinó de forma clara que habría que tomar medidas de priorización para organizar el trabajo respecto de los hechos cubiertos por la obligación de investigar, juzgar y sancionar y, (iii) se dejó la puerta abierta, a través de la utilización de cláusulas y lenguaje ambiguo, a la utilización de mecanismos de selección relacionados con aquellas personas que no fueran los máximos responsables de los crímenes más graves y representativos.

Frente a lo primero, se otorgaría la amnistía más amplia posible para delitos de rebelión y otros políticos y conexos ${ }^{[46]}$, tarea asignada a la SAI, y un tratamiento diferenciado, pero equilibrado y equitativo para los agentes del Estado y otros actores del conflicto ${ }^{[47]}$ para delitos similares, en este caso con competencia asignada de la SDSJ. Esto eliminaba del espectro de hechos a juzgar todos aquellos que, aunque no estaban cubiertos por la obligación internacional de investigar, juzgar y sancionar, sí debían ser abordados en el ámbito del derecho interno, pues la obligación de investigarlos de oficio persistía (figura 2). 


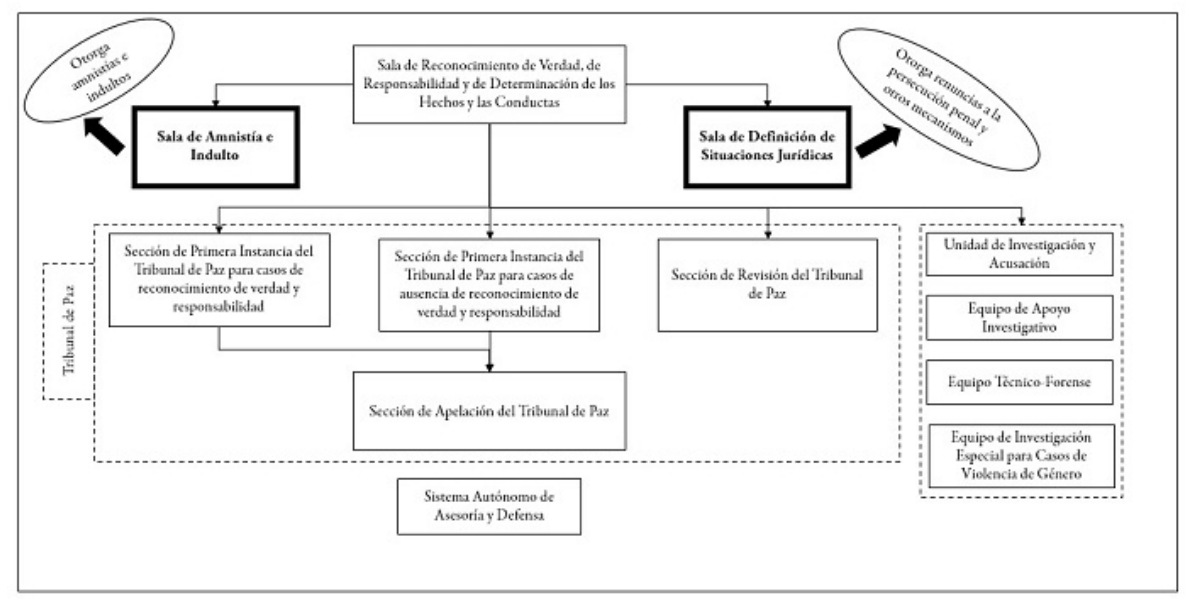

FIGURA 2.

Mecanismos de renuncia a la persecución penal básicos según el AFP Fuente: elaboración propia

En cuanto a lo segundo y lo tercero, (i) se reconoció de forma expresa la obligación del Estado colombiano de "investigar, esclarecer, perseguir y sancionar las graves violaciones del DIDH y las graves infracciones del $\mathrm{DIH}^{\text {"[48]; }}$; (ii) se determinó que hay delitos no amnistiables ni indultables ${ }^{[49]}$, específicamente los delitos de lesa humanidad, el genocidio, los graves crímenes de guerra, la toma de rehenes, las privaciones graves de la libertad, la tortura, las ejecuciones extrajudiciales, la desaparición forzada, el acceso carnal violento, la violencia sexual, la sustracción de menores, el desplazamiento forzado, el reclutamiento de menores y los delitos comunes no relacionados con la rebelión ${ }^{[50]}$. Frente a los delitos no amnistiables ni indultables de competencia de la JEP, (iii) se diseñó un esquema de sanciones con función restaurativa y reparadora que varían de acuerdo con el grado de verdad aportado, la gravedad de la conducta, los niveles de participación y responsabilidad y la contribución a la reparación ${ }^{[51]}$, todas ellas impuestas en el Tribunal de Paz. Todo bajo una asunción general: que cualquier tratamiento especial recibido en el marco de la JEP requiere del beneficiario "aportar verdad plena, reparar a las víctimas y garantizar la no repetición" ${ }^{[52]}$.

Este marco reducía significativamente el universo de casos que debe abordar la JEP, pues resuelve de plano las "violaciones menores" y establece los criterios para determinar cuáles son los delitos, hechos y conductas que caen dentro de la obligación de investigar, juzgar y sancionar. No obstante, lo inabarcable del universo permanecía y, por lo tanto, se consideraron necesarias medidas adicionales: una de ellas era la priorización. De acuerdo con lo pactado, la SRVR, que era la puerta de entrada a la Jurisdicción, tendría "las más amplias facultades para organizar sus tareas, integrar comisiones de trabajo, fijar prioridades, acumular casos semejantes y definir la secuencia en que los abordará" ${ }^{[53]}$. Mientras que la Unidad de Investigación y Acusación (en adelante UIA) podría también "organizar sus tareas, integrar comisiones de trabajo, fijar prioridades, acumular casos semejantes y definir la secuencia en que los abordará” ${ }^{[54]}$.

Esto implicaba un reconocimiento expreso de las dificultades que podría significar un abordaje caso-a-caso de los hechos y conductas cometidos en el marco del conflicto armado, Así como la determinación de una facultad, en cabeza de la propia JEP, de organizar su trabajo de manera que evitara la congestión judicial y tratara prioritariamente las conductas más graves y representativas ${ }^{[5]}$.

Tal habilitación para la SRVR y la UIA implica la posibilidad de cambiar el orden de decisión de los casos. De manera que, si bien el mecanismo no hace nada por reducir el universo de casos, hechos y conductas a abordar, sí permite que sean organizados a partir de criterios distintos al orden de llegada y, en ese sentido, decididos en conjunto. Decisión que en ningún caso podría ser arbitraria y sobre la cual la mesa de negociaciones dejó un margen de maniobra para el desarrollo e implementación normativa del AFP (figura 3). 


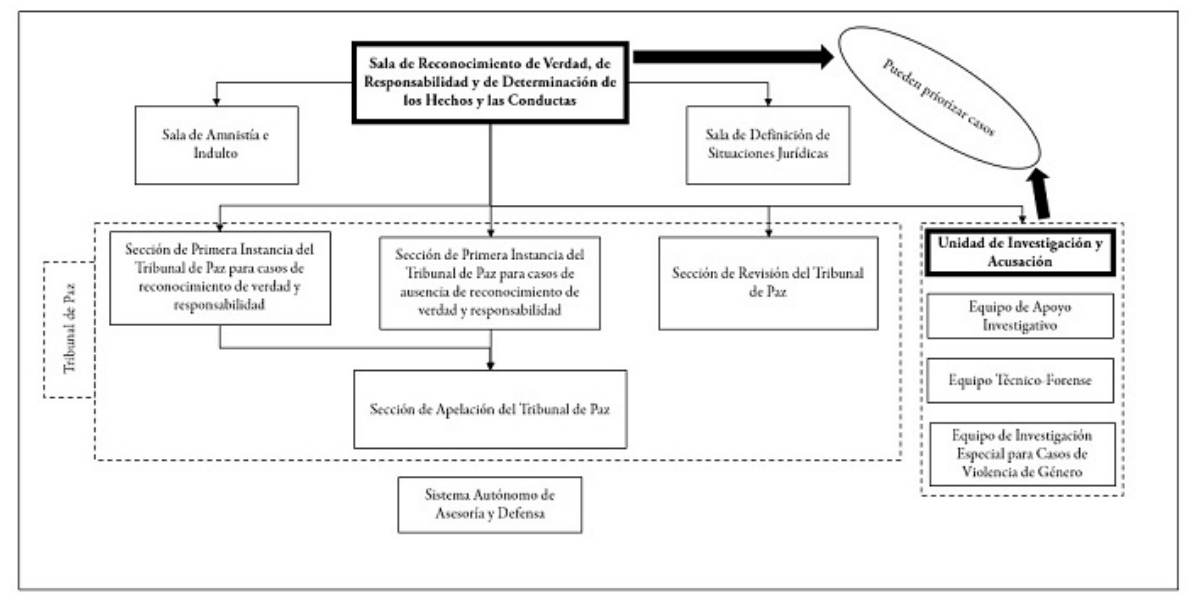

FIGURA 3.

Mecanismos de priorización según el AFP

Fuente: elaboración propia

Sin embargo, incluso con los mecanismos de amnistía, indulto, renuncia a la persecución penal y similares, y con la posibilidad de priorizar y agrupar casos para decidirlos, el universo seguía siendo inabarcable y se hacía necesario pensar en una opción adicional para reducirlo. Ahí es donde entró en juego la selección, pero en ese punto el AFP es menos claro, reflejando la falta de acuerdo entre las partes, especialmente por la reticencia de algunos sectores de las FARC y de los militares a seleccionar y enfocarse en los máximos responsables, y una decisión de dejar el problema para la implementación normativa del AFP.

Así, si se revisa el texto del AFP, la herramienta de selección de casos se sugiere a medida que se avanza en la forma que debía tomar la JEP y es mencionada en cuatro momentos: (i) para establecer que las víctimas tienen derecho a ser oídas al momento de la toma de una decisión sobre selección de $\operatorname{casos}^{[56]}$; (ii) de forma menos clara, en la posibilidad que tiene la SRVR de organizar su trabajo y "adoptar criterios de selección

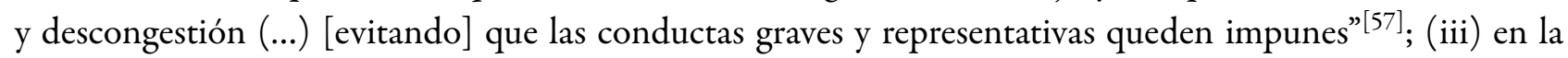
facultad que tiene la SDSJ de "determinar los posibles mecanismos procesales de selección y priorización para quienes no reconozcan verdad y responsabilidad" ${ }^{[58]}$ y, (iv) en la posibilidad que tiene la UIA de "adoptar criterios de selección" [59] en el marco de sus labores.

En otras partes del AFP se insinúa la forma en que ocurriría dicha selección, sin hacer mención explícita a ella. Por ejemplo, se determinó que la SRVR tenía la facultad de "decidir si las conductas no reconocidas serán sometidas a la Unidad de investigación y acusación para que, en caso de existir mérito para ello, se abra procedimiento de juicio ante el Tribunal. También podrá decidir remitir las conductas a la Sala de definición de situaciones jurídicas" ${ }^{[60]}$; aventurando una posibilidad de existencia de delitos no amnistiables o indultables y que no fueron reconocidos por los comparecientes que no iban a ser sometidos a consideración de la UIA para juicio. Disposición que se debe armonizar con la competencia para emitir resoluciones de conclusiones que tiene la SRVR ${ }^{[61]}$ y la obligación que le impone el propio AFP de "concentrarse desde un inicio en los casos más graves y las conductas o prácticas más representativas" ${ }^{[62]}$ a afectos de emitir dichas resoluciones de conclusiones. Y que se compagina con la función de remitir a la SDSJ una relación de personas "que no serán objeto de amnistía o indulto ni serán incluidas en la resolución de conclusiones" ${ }^{\text {"63] }}$ y otra con aquellas personas "a las que no habrá de exigírseles responsabilidades ante el Tribunal por las causas que fuere"[64]. Con la competencia correlativa de la SDSJ de tomar las decisiones necesarias "para definir la situación jurídica de quienes no fueron amnistiados ni indultados, ni han sido objeto de resolución de conclusiones" ${ }^{\text {"[65] }}$. 


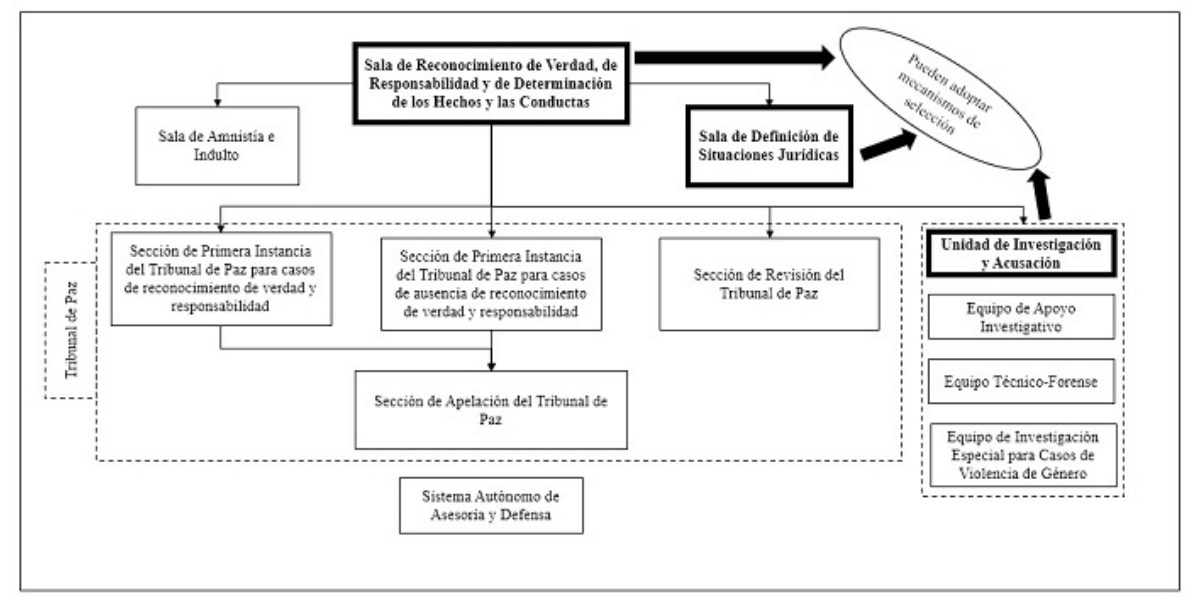

FIGURA 4.

Mecanismos de selección de casos según el AFP

Fuente: elaboración propia

Así, dentro del AFP aparece una dualidad particular frente al mecanismo de selección (figura 4). En algunos apartados se reconoce que habrá criterios de selección de casos y se faculta a ciertos órganos de la JEP para implementarlos, pero sin dejar tal facultad de forma clara y expresa. En otros, se presentan disposiciones aparentemente procedimentales que parecen indicar posibilidades de selección de casos, incluso frente a hechos y conductas no reconocidas por los comparecientes. La solución a esa dualidad, como en el pasado, fue dejar la tarea de concretizar los mecanismos de racionalización de la acción penal de priorización y selección a los órganos encargados de la implementación normativa del AFP y, en última instancia, a la propia JEP. Lo que incluía varios de los puntos más importantes del debate: cuáles serían los criterios utilizados para seleccionar y priorizar casos, qué nivel de concreción debían tener estos, quién debía tomar la decisión al respecto y con qué tipo de recursos contarían las víctimas, las partes y demás intervinientes para discutir una decisión de estas en un sentido u otro.

\section{Priorización y selección en práctica}

Luego de ratificado el AFP, el desafío era trasladar lo que estaba allí contenido a una fórmula normativa coherente que permitiera implementarlo de forma adecuada y cumplir los objetivos trazados. Esto necesariamente pasaba por acudir al Congreso de la República a desarrollarlo normativamente, algo que para el caso de los mecanismos de selección y priorización era importante. Esto dado el poco desarrollo que tuvieron en el AFP, la incertidumbre respecto a aspectos fundamentales, como los criterios a utilizar y, en general, por la importancia que estos tenían para la viabilidad del sistema de justicia.

En paralelo, a la mayor parte del desarrollo normativo, que casi dos años después de firmado el AFP no ha terminado, la JEP comenzó a funcionar y a tomar decisiones. Esto implicó, por ejemplo, para el caso de la SRVR, pensar y decidir sobre la forma en que organizarían su trabajo y los criterios de priorización a utilizar. El presente apartado desarrolla ambos temas, primero desde la implementación (3.1) y luego desde la puesta en práctica y la forma en que la JEP ha desarrollado el tema (3.2). 


\section{El desarrollo normativo de la jurisdicción especial para la paz y la priorización y selección}

El proceso de implementación normativa de la JEP, en teoría, debía seguir un esquema escalonado de expedición de normas que iban de lo general a lo particular. Así, en primer lugar, debía modificarse la Constitución para crear formalmente la JEP y sentar las bases constitucionales para su operación. Luego debería expedirse una ley estatutaria relacionada con la administración de justicia al interior de la JEP, y, finalmente, una ley de procedimiento que regulara expresamente la forma de tramitar los asuntos de competencia de la JEP (figura 5).

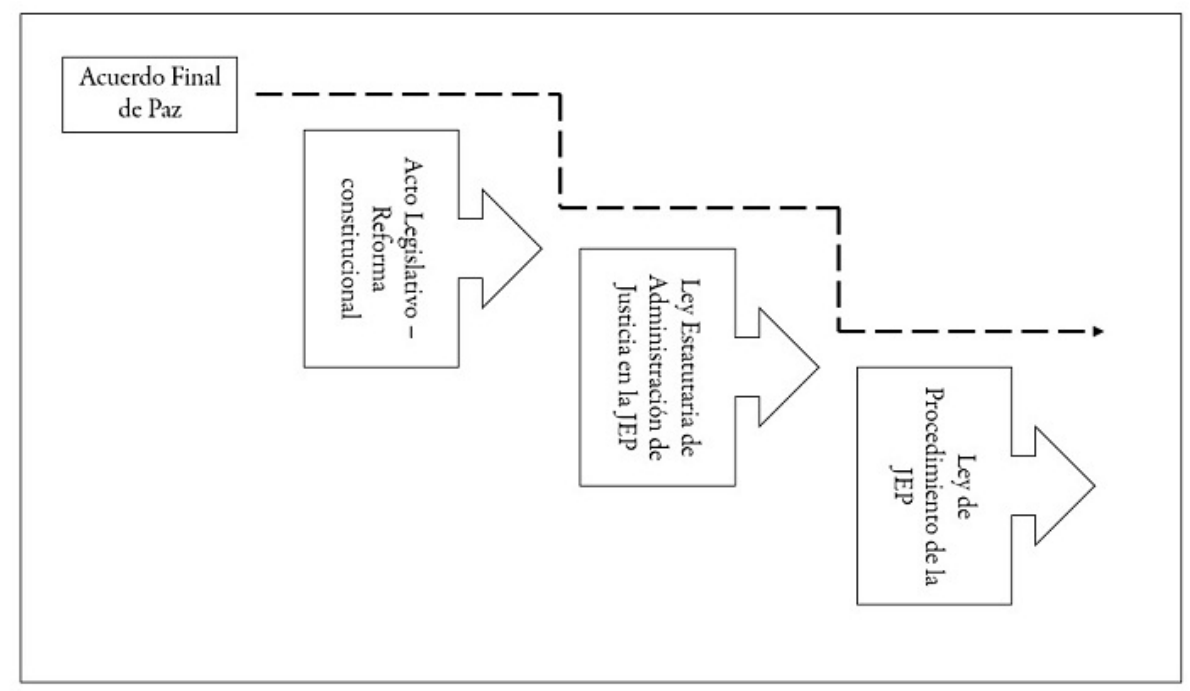

FIGURA 5.

Proceso de implementación normativa del AFP

Fuente: elaboración propia

El primer paso para la implementación normativa de la JEP, así como de todo SIVJRNR, fue el Acto Legislativo 01 de 2017, donde se agregó una serie de disposiciones transitorias a la Constitución Política de Colombia y se creó la JEP. Además, en lo pertinente, se modificó el artículo transitorio 66, que había sido introducido a través del Marco Jurídico para la Paz. Con el nuevo texto, quedo claro que "tanto los criterios de priorización como los de selección son inherentes a los instrumentos de justicia transicional” "66] y que, para el caso de la selección, "el Congreso de la República, por iniciativa del Gobierno Nacional, podrá mediante ley estatutaria determinar criterios de selección" ${ }^{[67]}$ para la JEP y la justicia ordinaria.

El Acto Legislativo 01 de 2017 fue sometido a control de constitucionalidad automático en la Corte Constitucional, la cual se vio en la necesidad de volver a pronunciarse sobre la obligación de investigar, juzgar y sancionar en el marco de una transición en Colombia, para verificar si era constitucional o no establecer la posibilidad de aplicar criterios de selección y priorización en el marco de la JEP. Allí, el tribunal explicó que

Con respecto al deber de investigar, juzgar y sancionar las graves violaciones a los derechos humanos y las infracciones al DIH, la Corte ha determinado que aunque en principio este deber en cabeza del Estado conlleva la obligación de desplegar la función persecutoria y represiva frente al fenómeno delictivo en toda su integridad y en todas sus manifestaciones, en contextos en los que se pretende poner fin a la violación masiva de derechos humanos, tal como ocurre en los períodos de transición producidos en el marco de un conflicto armado interno, este deber puede flexibilizarse, cuando, como contrapartida, se persigue una ganancia efectiva en términos de consecución de la paz, de la verdad, de la reparación a las víctimas, y de la obtención de garantías de no repetición, y cuando se preserva el mínimo irreductible de este deber, referido a la investigación, juzgamiento y sanción de los máximos responsables de los crímenes más graves y representativos ${ }^{[68]}$. 
Además, al llevar a cabo el análisis integral de lo dispuesto en el Acto Legislativo, encontró que este contenía restricciones a los derechos de las víctimas, entre otras la "potestad para concentrar la función persecutoria de los delitos en los máximos responsables de los crímenes más graves y representativos" ${ }^{\text {"69] }}$. No obstante, estas restricciones estaban dentro de lo constitucionalmente permitido, toda vez que (i) las pérdidas en términos de justicia se veían compensadas en términos de reconocimiento de la verdad y de reparación dentro de un sistema de condicionalidades, (ii) se mantenía el deber del Estado de imponer una sanción efectiva respecto de las más graves formas de criminalidad y, (iii) había mecanismos de reparación masiva diseñados y en ejecución ${ }^{[70]}$.

Esto llevó a la Corte Constitucional a declarar la exequibilidad de las disposiciones del Acto Legislativo 01 de 2017 relativas a la posibilidad de aplicar mecanismos de selección y priorización tanto en el marco de la JEP como de la justicia ordinaria. Algo que ya había hecho antes, con el Marco Jurídico para la Paz y la Ley de Justicia y Paz.

El siguiente paso en la implementación era la expedición de una ley estatutaria que regulara la administración de justicia en la JEP ${ }^{[71]}$. Respecto de los mecanismos de racionalización de la acción penal, en la ley estatutaria se entró en un nivel de especificidad mayor al del Acto Legislativo 01 de 2017, como es natural. Al tiempo que se dispuso que los mismos deberían respetar, por lo menos, tres principios: "i) transparencia en el proceso de selección de casos; ii) debida diligencia en las investigaciones que adelante la Unidad de Investigación y Acusación; iii) recurso efectivo por la Unidad de Investigación y Acusación para en su caso impugnar la decisión de no seleccionar un determinado caso que se considere prioritario" ${ }^{[72]}$.

En cuanto a la selección, se establecieron en el artículo 19 cinco criterios a utilizar por parte de la SDSJ y la SRVR para "concentrar el ejercicio de la acción penal en quienes tuvieron participación determinante en los hechos más graves y representativos" ${ }^{\text {" } 73]}$, a saber: (i) gravedad de los hechos, relacionado con el grado de afectación de derechos y la modalidad de comisión de la conducta; (ii) representatividad, referido a la capacidad de ilustración del modus operandi o las prácticas y patrones criminales; (iii) características diferenciales de las víctimas, especialmente las condiciones de vulnerabilidad en que pudieran estar inmersas por patrones históricos, sociales y culturales de discriminación; (iv) características de los responsables, específicamente si tuvieron una participación activa o determinante en los delitos y, (v) disponibilidad probatoria, relacionado con la calidad y cantidad de pruebas disponibles para probar un hecho y la dificultad para conseguir las que no estén a disposición ${ }^{[74]}$. Con respecto a aquellas personas y hechos que fueran objeto de selección, se dispuso que sería posible renunciar condicionadamente al ejercicio de la acción penal, siempre que (i) contribuyeran de manera eficaz al SIVJRNR; (ii) cumplieran las condiciones impuestas por la SDSJ o la SRVR; y (iii) suscribieran el acta de compromiso de no repetición y efectivamente la cumplieran ${ }^{[75]}$.

Por otro lado, la Ley ahondó en las competencias de la SDSJ para utilizar mecanismos de priorización ${ }^{[76]}$. Mientras que a la SRVR pareciera que incluso se le impuso una obligación directa de priorizar, no tanto una opción o facultad, pues se estableció que "a efectos de emitir su resolución [de conclusiones], deberá concentrarse desde un inicio en los casos más graves y en las conductas o prácticas más representativas"[77], al tiempo que se le entregaban las "más amplias facultades para organizar sus tareas, integrar comisiones de trabajo, fijar prioridades, acumular casos semejantes y definir la secuencia en que los abordará, así como adoptar criterios de descongestión" ${ }^{[78]}$.

El proyecto de ley estatutaria pasó a revisión de constitucionalidad en la Corte Constitucional, que decidió a través de la sentencia C-080 de 2018. Allí ahondó en asuntos relevantes para la aplicación de las herramientas de selección y priorización. Por ejemplo, confirmó que, en principio, se debería excluir la investigación caso a caso en la JEP y "privilegiar la construcción de macroprocesos" ${ }^{[79]}$, lo que indicaría que, efectivamente, se impuso una obligación de priorizar y una facultad de seleccionar, por lo menos en lo que tiene que ver con la SRVR y la UIA. 
Asimismo, la Corte explicó que quienes no fueran seleccionados podrían acceder a tratamientos penales especiales, como la suspensión de la ejecución de la pena, la renuncia condicionada, penas alternativas, entre otras, siempre que estén sometidos a un régimen de condicionalidad mayor a quienes únicamente cometieron delitos amnistiables. Y, además, decidió que una disposición del proyecto de ley estatutaria que establecía que no podría dejar de seleccionarse los delitos no amnistiables no tenía sentido, pues la facultad de seleccionar está creada precisamente para estos, para los demás existen las medidas de amnistía, indulto, renuncia a la persecución penal y demás. Así, "la selección opera frente a los responsables de los delitos más graves y representativos no amnistiables" ${ }^{[80]} \mathrm{y}$ siempre que primero se hayan agotado "por parte de la JEP los esfuerzos en la investigación de las graves violaciones a derechos humanos e infracciones al [DIH]"[81], momento en el cual se debe garantizar la aplicación de un estándar de debida diligencia. Luego de la investigación es que la JEP puede utilizar la facultad de seleccionar para "centrar sus esfuerzos en los máximos responsables y en quienes tuvieron una participación activa o determinante en los hechos más graves y representativos" ${ }^{[82]}$, de manera que se garantice en la mayor medida posible el derecho a la justicia dentro de un plazo razonable. Según la Corte, una disposición como la que contenía el proyecto de ley "hace inocua la facultad de selección" "[83] y, por lo tanto, se hizo necesario “condicionar la expresión 'delitos no amnistiables' en el sentido de que hace referencia exclusivamente a aquellos delitos que tengan la connotación de crímenes de lesa humanidad, genocidio o crímenes de guerra cometidos de manera sistemática, los cuales podrán ser atribuidos a los máximos responsables"[84].

El último paso en la implementación era la expedición de la Ley de Procedimiento de la JEP, que paradójicamente entró en vigencia antes que la ley estatutaria ${ }^{[85]}$. En este último conjunto de disposiciones se consagra el régimen procedimental a aplicar en la JEP y, para el caso de los mecanismos de selección y priorización se dejan claros algunos puntos que ya habían sido abordados anteriormente. En concreto, se confirmó y reguló el derecho de las víctimas a "ser oídas en los supuestos de priorización y selección de casos" ${ }^{[86]}$ ante la SRVR y se estableció la obligación de aplicar una metodología diferencial para delitos cometidos contra pueblos étnicos al revisar si se utilizan herramientas de selección y priorización, previo concepto de la Comisión Étnica ${ }^{[87]}$. Asimismo, se reguló la posibilidad de acumular casos ${ }^{[88]}$, se consagró la posibilidad de apelar las decisiones sobre selección de casos ${ }^{[89]}$ y se estableció la posibilidad de decretar la preclusión de un proceso en la SDSJ "cuando razonada y proporcionadamente no se haga necesario investigar, acusar o imponer la sanción de acuerdo a las finalidades de la JEP”[90].

La implementación normativa dejó entonces vacíos que la JEP debía llenar a través de su ejercicio jurisdiccional. En el paso por el Congreso de la República y la Corte Constitucional quedaron claridades y dudas sobre los mecanismos de selección y priorización para el desarrollo del sistema de justicia penal transicional.

Respecto de la priorización, el mecanismo mutó de ser una facultad que tenían los operadores de justicia, primero en la jurisdicción ordinaria y de Justicia y Paz y luego en la JEP, a ser considerada una obligación en algunos escenarios de la JEP: la SRVR y la UIA. Así, lo que se hizo en la implementación fue determinar los espacios en los que se debía o podía realizar la priorización, sin ahondar en las condiciones para la misma y manteniendo unos criterios mínimos para su correcta utilización: que permitiera concentrarse en los crímenes más representativos del conflicto armado y organizar de la mejor manera posible el trabajo de las distintas células judiciales.

Por el otro lado, sobre la selección apareció la ley estatutaria como el instrumento normativo por excelencia. Allí no sólo se confirman las facultades de las distintas salas de la JEP para llevarla a cabo, sino que se detallan los criterios que la deben guiar. Asimismo, con las decisiones de la Corte Constitucional quedó claro que la selección sólo debe operar luego de realizarse la investigación, organizada de la manera que se determine en el proceso de priorización, no antes. Así, la selección aparece claramente como una decisión de 
no perseguir penalmente a los responsables, más que de no investigar y, por lo tanto, debe estar permeada por el cumplimiento de estándares de debida diligencia en la investigación.

Las dudas aparecen entonces en varios niveles. Sobre la priorización quedó en el aire la forma que tomaría, los criterios a utilizar para tomar una decisión de priorización sobre otra y, en la práctica, las dimensiones que debería tener un macroproceso y la forma en que se tomarían decisiones investigativas al respecto. En cuanto a la selección, los puntos fundamentales giraban en torno a la posibilidad de la SDSJ de otorgar renuncias a la persecución penal o medidas equivalentes sin agotar antes el proceso de construcción de casos ante la SRVR, la forma en que se implementaría el régimen de condicionalidades mientras se surten los trámites y los distintos niveles de exigencia que este debía tener de acuerdo con la Corte Constitucional, así como el desarrollo concreto de la selección, las etapas procesales en que ocurriría, los dispositivos jurídicos a través de los cuales se materializaría, entre otros.

Esto llevó, naturalmente, a que la discusión se trasladara al ejercicio diario de la JEP, que debía tomar decisiones de priorización y selección como parte del cumplimiento de sus funciones.

\section{La puesta en práctica de la priorización y selección en la Jurisdicción Especial para la Paz}

La práctica de la JEP hasta el momento se ha centrado en las etapas iniciales de la labor de cada sala, por lo menos en lo que respecta a la investigación, juzgamiento y sanción de los máximos responsables por los crímenes más graves y representativos. En materia de mecanismos de racionalización de la acción penal, la actividad ha estado enfocada en la priorización, no en la selección. Hasta el momento no se cuenta con decisiones de selección o no de casos ni de renuncias a perseguir penalmente a personas que hayan cometido delitos no amnistiables, pero no vayan a ser sometidos a juicio por ellos ni recibirán sanciones o recibirán sanciones reducidas. Mientras tanto, la priorización sí ha sido objeto de atención, por lo menos en el trabajo de la SRVR, como se detalla a continuación.

Debido a la falta de desarrollo normativo específico del mecanismo de priorización, a lo primero que se tuvo que enfrentar la SRVR fue a determinar clara y detalladamente la forma en que lo implementaría, obviamente, bajo los parámetros de la jurisprudencia constitucional relevante. En ese sentido, el primer paso fue diseñar y poner en práctica una guía sobre criterios y metodología de priorización, un documento de política que "plantea los lineamientos básicos que guían el proceso de priorización de casos y situaciones al interior de la [SRVR]"[91].

El proceso de priorización diseñado por la SRVR consta de tres etapas: (i) agrupación; (ii) concentración y, (iii) priorización. Todas ellas guiadas por unos criterios para la priorización, que la SRVR decidió que fueran los mismos utilizados por el legislador para la selección y, además, basado en que "la priorización de casos y situaciones en la SRVRR se guía por el principio de simetría y tratamiento equitativo, equilibrado y simultáneo entre quienes hubieran participado en el conflicto armado interno" ${ }^{[92]}$ y en dos supuestos básicos: (i) que "todos los períodos y decisiones de priorización deben partir de la aplicación de los factores de competencia material, personal y temporal establecidos en la Constitución de forma transitoria en el artículo 7 del Acto Legislativo 01 de $2017^{\text {[93] }}$ y, (ii) que

(...) la priorización es, en esencia, un proceso de decisiones de estrategia y de gestión. Por consiguiente, las herramientas que permiten su ejercicio también deben serlo. Por esta razón, la priorización debe ser dinámica y progresiva, pensada a partir del flujo de información que reciba la SRVRR, pero también, desde la necesidad de rendir cuentas a la ciudadanía y de dotar de legitimidad a la justicia administrada por la JEP ${ }^{[94]}$.

Las etapas de agrupación y concentración del proceso de priorización son las herramientas para construir el universo de hechos competencia de la SRVR. Así, en ese momento lo que se hace es "construir y agrupar en 
distintas categorías, universos provisionales de hechos que cumplan con los factores de competencia material, personal y temporal" ${ }^{[95]}$. Para lograrlo, se acude a las diversas fuentes de información con que cuenta la SRVR, entre ellas: (i) los informes entregados por instituciones; (ii) el informe presentado por el Secretario Ejecutivo de la JEP; (iii) los informes entregados por organizaciones de víctimas, de derechos humanos y étnicas; (iv) las versiones voluntarias de los comparecientes; (v) el inventario de hechos elaborado por la Fiscalía General de la Nación; (vi) las bases de datos institucionales; (vii) los testimonios; (viii) los expedientes judiciales recibidos, entre otras ${ }^{[96]}$.

Delimitado el universo de hechos de competencia de la SRVR, de los cuales se excluyeron no sólo los que no correspondían a laJEP, sino los que eran de competencia de la SAI y la SDSJ, se pasa a la fase de priorización en estricto sentido, que es cuando se aplican los criterios de priorización para establecer el orden de atención para los hechos. Los criterios que se utilizan en la estrategia de priorización parten de dos dimensiones: el impacto y la disponibilidad de la información; y el componente de impacto tiene dos componentes, el subjetivo y el objetivo.

Desde el criterio subjetivo de impacto, la SRVR debe tener en cuenta (i) la situación de vulnerabilidad de las víctimas; (ii) el impacto diferenciado en los pueblos étnicos y sus territorios; (iii) el impacto diferenciado en otros sujetos colectivos y, (iv) la representatividad de los presuntos responsables. Mientras tanto, el criterio objetivo de impacto implica evaluar: (i) la gravedad de los hechos; (ii) la magnitud de la victimización y, (iii) la representatividad de los hechos (figura 6). Una vez que se tienen en cuenta ambos criterios, se hace posible y necesario "identificar y analizar los planes o políticas, elementos de sistematicidad, y patrones de macrocriminalidad" ${ }^{[97]}$. Por su parte, el criterio complementario de disponibilidad de la información puede ser evaluado, pero siempre dentro del marco de los estándares sobre la obligación de investigar, juzgar y sancionar y partiendo del reconocimiento de que la ausencia de información incluso "puede denotar la existencia de elementos que lleven a su priorización" ${ }^{[98]}$.

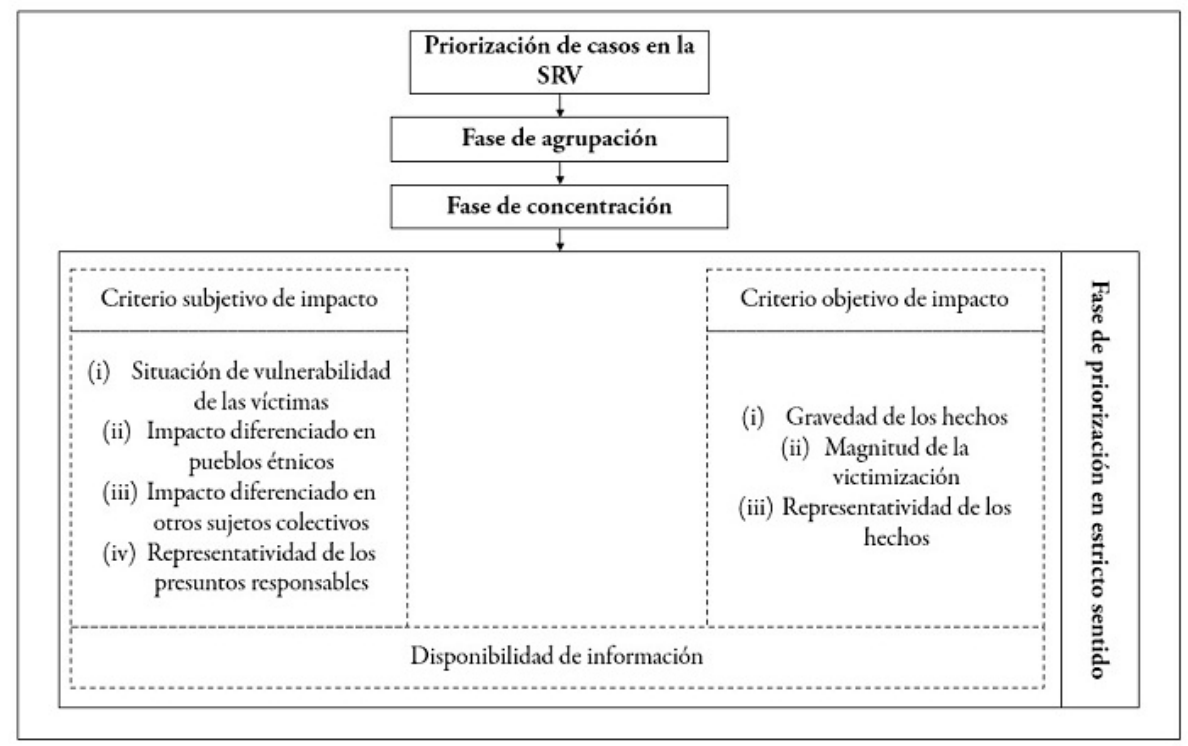

FIGURA 6.

Proceso de priorización en la SRVR

Fuente: elaboración propia

La SRVR comenzó su trabajo basada en la guía adoptada y, a través de este procedimiento, a la fecha de escritura de este texto había priorizado siete casos, a saber: (i) Caso 001-Retención ilegal de personas por parte de las FARC.-EP; (ii) Caso 002-Situación municipios de Ricaurte, Tumaco y Barbacoas del Departamento de Nariño; (iii) Caso 003-Muertes ilegítimamente presentadas como bajas en combate por agentes del Estado; (iv) Caso 004-Situación territorial de la Región de Urabá; (v) Caso 005-Situación territorial Norte 
del Cauca en los municipios de Santander de Quilichao, Suárez, Buenos Aires, Morales, Caloto, Corinto, Toribío y Caldono; (vi) Caso 006-Victimización de miembros de la Unión Patriótica (UP) y, (vii) Caso 007Reclutamiento de niñas y niños en el conflicto armado.

Como se puede observar, la SRVR ha utilizado, hasta el momento, dos tipos de acercamiento a los macrocasos a priorizar. Por un lado, están aquellos delimitados en razón de una conducta representativa, sea la presentación ilegítima de una baja como dada en combate, la retención ilegal de personas, el reclutamiento de niñas y niños o el exterminio de una agrupación política. Mientras que, por el otro, adopta un enfoque territorial, tendiente a analizar lo sucedido en una zona específica de manera más o menos comprehensiva. Así, además de tomar una decisión sobre los hechos, conductas y personas a priorizar desde el punto de vista de los criterios de priorización, la SRVR también toma decisiones estratégicas sobre el alcance y la delimitación de los macrocasos.

Este es el desarrollo que hasta el momento ha tenido el mecanismo de priorización en la práctica efectiva de la JEP.

Como se explicará a continuación, las decisiones sobre priorización tomadas hasta el momento corren el riesgo de transformarse en una selección de facto si no se aborda el asunto de las situaciones, casos y responsables que serán seleccionados para pasar al Tribunal de Paz y los que no. Si la JEP no da pautas claras y actúa en consecuencia respecto de los asuntos que seleccionará y los que no, el paso del tiempo podría terminar siendo el único criterio relevante para la selección. Hasta el momento, luego de casi dos años de funcionamiento, la jurisdicción cuenta con siete macrocasos, pero no ha hecho manifestación alguna respecto a la forma en que excluirá situaciones, casos o responsables del juzgamiento y sanción. Para una herramienta de justicia que tiene un marco temporal de funcionamiento definido y estrecho, la falta de una decisión a este respecto podría generar problemas operativos, jurídicos y de legitimidad si el paso del tiempo obliga a tomarla a último momento.

\section{Una propuesta para la aplicación de los criterios de selección}

A diferencia de la priorización, la selección continúa en un estado de latencia, dada su naturaleza y el mandato constitucional de agotar primero actividades suficientes de investigación con debida diligencia para tomar decisiones informadas y respetuosas de los derechos de las víctimasde los casos que no serán objeto de persecución penal, a pesar de no ser amnistiables los delitos cometidos. A esto se suma la falta de claridad tanto en el AFP como en las normas de implementación del SIVJRNR y la JEP y, por lo tanto, la amplitud del margen de discrecionalidad con que cuentan los operadores para tomar decisiones al respecto.

Estos factores abren el panorama para cuatro posibles formas de abordar la selección como herramienta de racionalización de la acción penal en la JEP: (i) Que la JEP seleccione rápidamente las situaciones en las que centrará su trabajo y esa decisión sea definitiva, lo cual implica expresamente excluir de su competencia todo aquello no seleccionado; (ii) que la JEP lleve a cabo un proceso inicial de selección, pero que no sea completamente cerrado y definitivo, sino que permita un mecanismo para revisitar decisiones de forma excepcional y ajustado a unos criterios limitados que expresamente defina la JEP; (iii) que la JEP se concentre en priorizar casos y, a partir del trabajo realizado, tome decisiones de selección con posterioridad o, (iv) que la JEP decida no seleccionar y sea el paso del tiempo y el cumplimiento del término de duración de la jurisdicción los que decidan qué casos no serán sometidos al Tribunal de Paz.

Dado el diseño normativo y la principialística que rige la JEP, la mejor situación posible respecto de la utilización de la selección como herramienta de racionalización de la acción penal parece ser la segunda. Aquella en la que la JEP decide de forma oportuna, transparente y motivada sobre la selección de situaciones, casos y responsables, se somete al escrutinio de las víctimas, sus representantes y la sociedad en general, y deja 
la puerta abierta para revisitar excepcionalmente sus decisiones si en el transcurso de su labor investigativa encuentra la necesidad de reconsiderar la exclusión de una situación o un caso.

Dada la falta de desarrollo y la importancia del asunto, en el presente apartado nos permitimos presentar algunas propuestas para la implementación del mecanismo de selección en la JEP que busca la materialización de ese escenario. Esto con miras a cumplir dos objetivos: (i) operativizar la selección y permitir que la JEP pueda desarrollar su mandato de dar cierre jurídico al conflicto armado interno de forma efectiva; y (ii) respetar los parámetros sobre el deber de investigar, juzgar y sancionar y el derecho de las víctimas a la justicia que ya fueron abordados previamente.

Como ya se explicó, el estándar constitucional colombiano exigía establecer criterios para la selección por vía de una ley estatutaria. El Congreso de la República efectivamente hizo esto en la Ley Estatutaria para la Administración de Justicia en la JEP, dejando cinco criterios para guiar la concentración del ejercicio de la acción penal en quienes tuvieron participación determinante en los hechos más graves y representativos: (i) gravedad de los hechos; (ii) representatividad; (iii) características diferenciales de las víctimas; (iv) características de los responsables y, (v) disponibilidad probatoria.

Si se revisan estos criterios y se comparan con los de priorización, veremos que hay una similitud remarcable. Dentro de los criterios subjetivos que se encuentran para la priorización están las características diferenciales de las víctimas, de la misma manera que en la selección. Mientras que dentro de los criterios objetivos para la priorización aparecen la gravedad y la representatividad, que también están en la selección. Esto hace que sea necesario operativizar los criterios de selección, de manera que puedan servir para el objetivo que se supone sirven y se diferencien de la priorización. Definirlos y aplicarlos de forma idéntica llevaría a que la priorización fuera una selección de facto y la selección en estricto sentido una simple validación de la priorización.

Así, lo que aquí se propone es un modelo escalonado de aplicación de los criterios de selección que permita diferenciar las distintas etapas en el proceso de racionalización de la acción penal, operativice los mecanismos y garantice una deliberación amplia y profunda sobre la forma en que se selecciona, de la forma como aparece en la figura 7 .

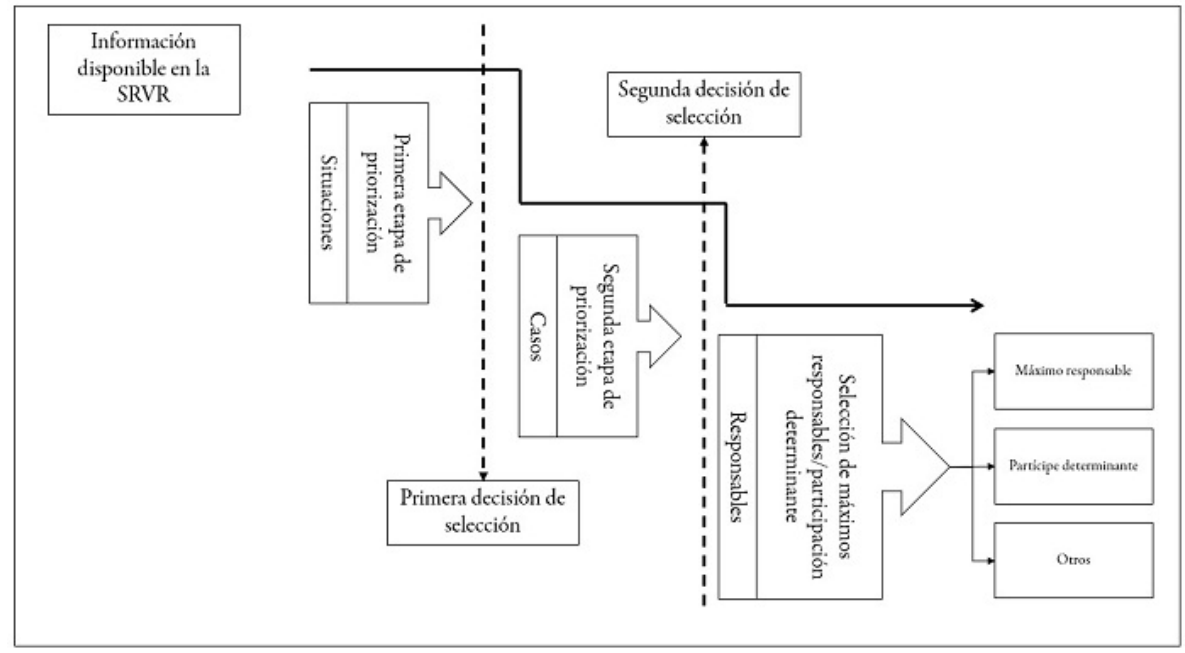

FIGURA 7.

Proceso de priorización y selección escalonado

Fuente: elaboración propia

Esta propuesta parte de una combinación de los dos mecanismos de racionalización pertinentes, la priorización y la selección. Así, en primer lugar, se deberían priorizar situaciones, como ha hecho hasta el momento la SRVR; para lo cual se deberían tener en cuenta tanto los criterios objetivos como subjetivos establecidos en la guía de criterios y metodología de priorización de casos y situaciones. En este momento, luego de la priorización de las situaciones que la Sala considere necesarios y suficientes para caracterizar 
de forma completa el conflicto armado colombiano, se haría necesaria la toma de una primera decisión de selección. Allí la SRVR debería explicar cuáles situaciones decidió finalmente seleccionar y cuáles no, para lo cual debería, con anterioridad, haber escuchado a las víctimas, sus representantes, las organizaciones de la sociedad civil y demás agentes interesados, para conocer su postura frente a las situaciones seleccionadas y no seleccionadas. Esto le daría cierre a la primera etapa del trabajo de la SRVR y dotaría de certeza y seguridad jurídica al desarrollo de las siguientes etapas.

Posteriormente, se pasaría a una segunda etapa de priorización, en la que se concreten los macrocasos a partir de los criterios de gravedad, magnitud, representatividad y vulnerabilidad e impacto diferencial en las víctimas, de manera que se cuente con un universo de casos, perpetradores y víctimas que pueda manejarse desde el punto de vista de la decisión judicial. Luego de ese momento de concreción se debería tomar una segunda decisión de selección, esta vez de forma específica para cada una de las situaciones. Allí la SRVR establecería de forma clara los casos con los que continuaría y los que descartaría en aplicación de los criterios de selección arriba mencionados. Como en la etapa anterior, para la toma de una decisión como esta sería necesaria la apertura de un espacio amplio y profundo de participación en el que los distintos actores interesados planteen sus posturas y opiniones y sus posiciones sean escuchadas y tenidas en cuenta.

Finalmente, en una última etapa, lo importante debería ser la determinación de los máximos responsables de los actores en los delitos cometidos dentro de los macrocasos. Es decir, luego de las dos etapas de la priorización ya debería estar claro que la SRVR está en presencia de hechos y conductas suficientemente graves, de magnitud relevante, representativos en el conflicto armado colombiano y en donde las víctimas tienen niveles de vulnerabilidad o de impacto diferencial suficientes. Así que lo que quedaría es centrarse en los máximos responsables por los delitos cometidos y en quienes participaron de forma determinante en ellos.

De acuerdo con lo anterior, para seleccionar en esta última etapa se debería llevar a cabo un análisis de dos niveles: a lo que se debería acudir en el primer nivel es al criterio de características de los responsables, concretamente, a determinar si la persona es un máximo responsable o no y, en caso de no ser un máximo responsable, a determinar si tuvo una participación determinante o no en los hechos. Quienes no ostenten ninguna de las dos calidades, es decir, ni son máximos responsables ni tuvieron una participación determinante en los hechos, deberían ser objeto de definición de situación jurídica permanente a través de mecanismos como la renuncia a la persecución penal. Mientras tanto, quienes sí sean máximos responsables y/o partícipes determinantes, deberían continuar con la ruta a través de la JEP, sea que acepten su responsabilidad o no, y recibir las sanciones pertinentes ${ }^{[99]}$.

Lo único que quedaría pendiente sería definir el rol del criterio de disponibilidad probatoria dentro del proceso de selección, el segundo nivel del análisis. Este sólo debería ser relevante en la decisión que tome la UIA (que como ya se explicó, también puede seleccionar) de llevar a juicio o no a alguien que no reconoce su responsabilidad ante el Tribunal de Paz y constituye el segundo nivel de análisis en la tercera etapa de selección. Es decir, sólo debería servir en caso de no contar con un caso fuerte para la judicialización coactiva de un compareciente y siempre que dicha decisión sea motivada y pueda ser controvertida por las víctimas.

Esta forma de aplicación de los criterios de priorización y selección debería servir para que la JEP pueda abordar su trabajo de forma ordenada, pero respetando los estándares sobre investigación, juzgamiento y sanción que la gobiernan. En ese sentido, deberían ser de aplicación cíclica, es decir, se deberían repetir los pasos tantas veces como sea necesario, hasta que las situaciones a priorizar no cumplan con los criterios de gravedad, representatividad y vulnerabilidad e impacto diferenciado y, por lo tanto, sea posible tomar una decisión de selección sobre ellas. 


\section{Conclusiones}

La historia de la implementación en Colombia de mecanismos de racionalización de la acción penal como respuesta para la transición va más atrás que la implementación del AFP. Desde el momento en que verificó el estancamiento del procedimiento de Justicia y Paz, dado el volumen de casos y las características especiales que los rodeaban, aun cuando se contaba con la confesión de los postulados, el Estado colombiano buscó soluciones en la concentración sobre los crímenes más graves, respecto de los máximos colombianos. Esto también en línea con su obligación internacional de investigar, juzgar y sancionar con debida diligencia, incluyendo la develación de patrones de macrocriminalidad y estructuras criminales.

Este cambio de enfoque en la política criminal, que luego se trasladó a la justicia ordinaria y a los instrumentos para nuevas transiciones (Marco Jurídico para la Paz) crearon tensiones con distintos sectores. La falta de claridad del Sistema Interamericano de Derechos Humanos y la Corte Penal Internacional respecto de la posibilidad de renunciar a la persecución, así como la desconfianza de sectores de defensa de derechos humanos hacia las verdaderas intenciones estatales llevaron a duros debates sobre la posibilidad o no de racionalizar la acción penal, especialmente a través de la selección. La Corte Constitucional medió en el debate en distintas oportunidades, algunas con más opacidades que claridades, pero al final dejó clara la posibilidad de priorizar y seleccionar en algunos casos.

Con la firma del AFP un nuevo modelo de justicia penal para la transición fue diseñado. Allí, como es natural, se volvió a acudir a figuras de racionalización de la acción penal, concretamente, mecanismos de priorización robustos y de selección bastante ambiguos en el texto acordado. La diferencia con este nuevo escenario es que se partía de una base distinta: ya la Corte Constitucional había establecido el piso jurídico para la aplicación de medidas de selección y priorización y eso parecería haber sido aceptado por organismos internacionales.

La implementación normativa demostró que ese enfoque seguro en la priorización y la debilidad de la selección pondría en dificultades al Congreso de la República para determinar de la mejor manera posible cómo establecer ambos mecanismos. En el estado actual de la implementación, el legislador reforzó la posibilidad de priorizar e, incluso, la Corte Constitucional parece haberla entendido no tanto como una facultad, sino como una obligación. Mientras tanto, la selección continúa en vilo, especialmente luego de la objeción gubernamental al artículo 16 del proyecto de ley estatutaria de la JEP.

Mientras tanto, la JEP, concretamente la SRVR, en su trabajo diario concretizó el modelo de priorización en una guía de política pública y comenzó a aplicarlo con la determinación de siete macrocasos en los que concentraría su trabajo en este primer momento. La selección todavía no ha tenido su turno, por varias razones. Por una parte, la disposición que consagra los criterios de selección está en el proyecto de ley estatutaria, que aún no se encuentra en vigencia. Por otra, el trabajo de la SDSJ ha estado centrado hasta el momento en la admisión de personas a la JEP y en la concesión de beneficios transitorios, no tanto en los beneficios definitivos. Además, la SRVR se encuentra aún en las etapas preliminares de su trabajo y no está cerca de emitir resoluciones de conclusiones ni de remitir los listados de personas que no serán objeto de persecución a la SRVR.

Esa falta de determinación sobre la selección que hay tanto en el AFP como en las normas de implementación deja un espacio de decisión tan amplio para la JEP que se hace necesario un debate concienzudo y amplio al respecto, antes de abordarla. Así, las perspectivas de desarrollo de los mecanismos de racionalización de la acción penal parecen diferentes.

La priorización parece contar con un consenso bastante amplio sobre su legitimidad y necesidad, no tanto en la forma en que debe llevarse a cabo en la práctica. Mientras tanto, la selección continúa en disputa, tanto en el Congreso y la Corte Constitucional como en el debate público, aunque por ahora parece haber claridades sobre su legitimidad desde el punto de vista constitucional y de derecho internacional. 


\section{Bibliografía}

Acto Legislativo 01 de 2017 [Congreso de Colombia]. Por medio del cual se crea un título de disposiciones transitorias de la constitución de una paz estable y duradera y se dictan otras disposiciones. 4 de abril de 2017.

Allen S. Weiner, Ending Wars, Doing Justice: Colombia, Transitional Justice, and the International Criminal Court, 52 Stanford Journal of International Law, n. ${ }^{\circ} 2,211-241$ (2016). https://law.stanford.edu/publications/ending-wa rs-doing-justice-colombia-transitional-justice-and-the-international-criminal-cour/

Carlos Santiago Nino, Juicio al mal absoluto ehasta dónde debe llegar la justicia retroactiva en casos de violaciones masivas de los derechos humanos? (Siglo XXI Editora Iberoamericana, 2015).

Claudia López Díaz, Selección y priorización de delitos como estrategia de investigación en la justicia transicional, 42 Revista Facultad de Derecho y Ciencias Políticas, n. ${ }^{\circ} 117$, 515-579 (2012). http://www.scielo.org.co/pdf/rfdc $\mathrm{p} / \mathrm{v} 42 \mathrm{n} 117 / \mathrm{v} 42 \mathrm{n} 117 \mathrm{a} 08 . \mathrm{pdf}$

Comisión Interamericana de Derechos Humano (CIDH), Verdad, justicia y reparación: Cuarto informe sobre la situación de derechos humanos en Colombia, OEA/Ser.L/V/II. Doc. 49/13.31 de diciembre de 2013. https:// www.oas.org/es/cidh/docs/pdfs/justicia-verdad-reparacion-es.pdf

Corte Constitucional. Sentencia C-080 de 2018. (M.P. Antonio José Lizarazo Ocampo; 15 de agosto de 2018).

Corte Constitucional. Sentencia C-579 de 2013. (M.P. Jorge Ignacio Pretelt Chaljub; 28 de agosto de 2013).

Corte Constitucional. Sentencia C-673 de 2005. (M.P. Clara Inés Vargas Hernández; 30 de junio de 2005).

Corte Constitucional. Sentencia C-674 de 2017. (M.P. Luis Guillermo Guerrero Pérez; 14 de noviembre de 2017).

Delegación de Paz de las FARC-EP, Sobre un Marco Jurídico fuera de contexto (2013). http://pazfarc-ep.org/comun icadosfarccuba/item/1388-sobre-un-marco-juridico-fuera-de-contexto.html

Estado de Colombia y FARC-EP. Acuerdo Final para la Terminación del Conflicto y la Construcción de una Paz Estable y Duradera (2016).

Fatou Besouda, Escrito de Amicus Curiae de la Fiscal de la Corte Penal Internacional sobre la Jurisdicción Especial para la Paz (2017). http://cr00.epimg.net/descargables/2017/10/21/17135b6061c7a5066ea86fe7e37ce26a.pdf?in $\mathrm{t}=$ masinfo

Hernando Valencia Villa, La Ley de Justicia y Paz de Colombia a la luz del Derecho Internacional de los Derechos Humanos (Centro de Investigación para la Paz [CIP-FUHEM], 2005). https://www.fuhem.es/media/cdv/file/ biblioteca/Informes/Azules/VALENCIA,\%20Hernando,\%20Ley\%20justicia\%20y\%20Paz\%20Colombia.pdf

Hugo Fernando Saidiza et al., Informe sobre criterios de selección y priorización en la investigación y judicialización en contextos de justicia transicional, Avocats sans frontieres Canada (2018).

International Human Rights Institute, Chicago Council on Global Affaire, Istituto Superiore Internazionale di Scienze Criminali \& Association Internationale de Droit Pénal, Los Principios de Chicago sobre Justicia Transicional (2007). https://biblioteca.iidh-jurisprudencia.ac.cr/index.php/documentos-en-espanol/verdad-justicia-y-repar acion/1312-los-principios-de-chicago-sobre-justicia-transicional/file

Iván Orozco, Pronunciamiento público ante la Corte Constitucional. Notas no publicadas, en archivo de los autores (27 de mayo de 2014).

Jamie Rowen, "We don't believe in Transitional Justice": Peace and the politics of Legal Ideas in Colombia, 42 Law and Social Inquiry. Journal of the American Bar Foundation, 3, (2017).

JEP. SRVR. Criterios y metodología de priorización de casos y situaciones en la Sala de Reconocimiento de Verdad, de Responsabilidad y de Determinación de los Hechos y Conductas. 28 de junio de 2018.

Ley 1592 de 2012. Por medio de la cual se introducen modificaciones a la Ley 975 de 2005 "por la cual se dictan disposiciones para la reincorporación de miembros de grupos armados organizados al margen de la ley, que contribuyan de manera efectiva a la consecución de la paz nacional y se dictan otras disposiciones para acuerdos humanitarios" y se dictan otras disposiciones. 3 de diciembre de 2012. D. O. 48.633.

Ley 1922 de 2018. Por medio del cual se adoptan unas Reglas de Procedimiento para la Jurisdicción Especial para la Paz. 18 de julio de 2018. D. O. 50658. 
Ley 1957 de 2019. Ley Estatutaria de la Administración de Justicia en la Jurisdicción Especial para la Paz. 6 de junio de 2019. D. O. 50976.

Louise Mallinder, Amnesty, human rights and political transitions: Bridging the peace and justice divide (Hart Publishing, 2008).

Luis Miguel Gutiérrez Ramírez, La obligación internacional de investigar, juzgar y sancionar graves violaciones a los derechos humanos en contextos de justicia transicional, 16 Estudios Socio-Jurídicos, n. 20 23-60 (2014). https:// doi.org/10.12804/esj16.02.2014.01

Marco Antonio Macana \& Luis Antonio Castro Alegría, Criterios de selección de crímenes internacionales en la justicia transicional con respecto al conflicto armado no internacional en Colombia, 23 Papel político, n. ${ }^{\circ}$ 1,91-130 (2018). https://doi.org/10.11144/Javeriana.papo23-1.csci

Mariano Gaitán, Prosecutorial discretion in the investigation and prosecution of massive human rights violations: Lessons from the Argentinian experience, 32 American University International Law Review, n. ${ }^{\circ}$ 2, 540-568 (2018). http s://digitalcommons.wcl.american.edu/auilr/vol32/iss2/6/

Mark Freeman, Necessary evils: Amnesties and the search for justice (Cambridge University Press, 2010). https://do i.org/10.1017/CBO9780511691850

Mirna Goransky \& Ana Maria Luisa Pique, (The Lack of) Criteria for the Selection of Crimes Against Humanity Cases: The Case of Argentina, En Morten Bergsmo, Criteria for Prioritizing and Selecting Core International Crimes Cases, Torkel Opsahl Academic EPublisher, Oslo (2010).

Morten Bergsmo, Ed., Criteria for prioritizing and selecting core international crimes cases (Torkel Opsahl Academic EPublisher, 2010).

Morten Bergsmo \& María Paula Saffon, Enfrentando una fila de atrocidades pasadas. ¿Cómo seleccionar y priorizar casos de crímenes internacionales centrales?, en Selección y priorización como estrategia de persecución en los casos de crímenes internacionales. Un estudio comparado (Kai Ambos ed., ProFis-GIZ, 2011).

Nelson Camilo Sánchez León, El rol del derecho penal y de la pena en la transición colombiana. Un análisis jurídico de los debates actuales sobre la penalización de crímenes graves en el conflicto armado colombiano (Centro de Estudios de Derecho, Justicia y Sociedad, 2015).

Nelson Camilo Sánchez \& Rodrigo Uprimny, El Marco Jurídico Para La Paz: ¿Cheque En Blanco O Camisa De Fuerza Para Las Negociaciones De Paz?, en Justicia Para La Paz: Crímenes Atroces, Derecho a La Justicia Y Paz Negociada (Rodrigo Uprimny Yepes, Luz María Sánchez Duque and Nelson Camilo Sánchez León eds., Centro de Estudios de Derecho, Justicia y Sociedad, Dejusticia, 2014).

Nicolás Palau van Hissenhoven, Trámite de la Ley de Justicia y Paz. Elementos para el control ciudadano al ejercicio del control político (Fundación Social, 2006).

Paul Seils, Propuesta de criterios de selección y priorización para la ley de Justicia y Paz en Colombia (2012). https://www.ictj.org/sites/default/files/ICTJ-COL-PaulSeils-Propuesta\%20de\%20criterios\%20de\%2 0selecci\%C3\%B3n\%20y\%20priorizaci\%C3\%B3n-2012.pdf

Paul Seils, Squaring Colombia's Circle: The Objectives of Punishment and the Pursuit of Peace (2015), https://www.ictj.org/publication/squaring-colombia-circle-objectives-punishment-peace?utm_source $=$ Subscriber + Master+List\&utm_campaign=70694f8e9e-SSR_Weekly_Dec20_2015\&utm_medium=email \&utm_term=0_6ebc4afdf4-70694f8e9e-122556493

Richard Arens, Nuremberg and group Prosecution, 1951 Washington University Law Review, n. ${ }^{\circ} 3,229-357$ (1951). h ttps://openscholarship.wustl.edu/cgi/viewcontent.cgi?article=3690\&context=law_lawreview

Rodrigo Uprimny Yepes \& Nelson Camilo Sánchez León, Beyond the Binary. Securing Peace and Promoting Justice after Conflict (Centro de Estudios de Derecho, Justicia y Sociedad, 2019).

Rodrigo Uprimny Yepes, Luz María Sánchez Duque \& Nelson Camilo Sánchez León, Justicia para la paz. Crímenes atroces, derecho a la justicia y paz negociada (Centro de Estudios de Derecho, Justicia y Sociedad, 2013).

Sabine Michalowski \& Jorge Parra Norato, Los “máximos responsables” en el marco de la Jurisdicción Especial para la Paz. Documento no publicado, en archivo de los autores.

Tatiana Rincón, Verdad, justicia y reparación: La justicia de la Justicia Transicional (Ed. Universidad del Rosario 2010). 
Ted Picconne, Peace with Justice: The Colombian Experience with transitional Justice. Foreign Policy at Brookings (2019).

University of Ulster's Transitional Justice Institute. Las pautas de Belfast sobre amnistía y responsabilidad (2012).

Xabier Agirre, Prosecuting the most responsable for international crimes. Dilemmas of definition and prosecutorial discretion, en Protección internacional de los derechos humanos y Estado de Derecho, Bogotá (Joaquín González ed., Grupo Editorial Ibañez, 2009).

\section{Notas}

[1] Estado de Colombia y FARC-EP. Acuerdo Final para la Terminación del Conflicto y la Construcción de una Paz Estable y Duradera (2016).

[2] Ver, entre otros, Paul Seils, Squaring Colombia's Circle: The Objectives of Punishment and the Pursuit of Peace (2015); Nelson Camilo Sánchez León, El rol del derecho penal y de la pena en la transición colombiana. Un análisis jurídico de los debates actuales sobre la penalización de crímenes graves en el conflicto armado colombiano (Centro de Estudios de Derecho, Justicia y Sociedad, 2015).

[3] Tatiana Rincón, Verdad, justicia y reparación: La justicia de la Justicia Transicional (Ed. Universidad del Rosario 2010).

[4] Ted Picconne, Peace with Justice: The Colombian Experience with transitional Justice. Foreign Policy at Brookings (July 2019); Jamie Rowen, "We don't believe in Transitional Justice": Peace and the politics of Legal Ideas in Colombia, 42 Law and Social Inquiry. Journal of the American Bar Foundation, 3, (2017).

[5] Allen S. Weiner, Ending Wars, Doing Justice: Colombia, Transitional Justice, and the International Criminal Court, 52 Stanford Journal of International Law, n. ${ }^{\circ}$ 2, 211-241 (2016).

[6] Carlos Santiago Nino, Juicio al mal absoluto chasta dónde debe llegar la justicia retroactiva en casos de violaciones masivas de los derechos humanos? (Siglo XXI Editora Iberoamericana, 2015).

[7] Morten Bergsmo, Ed., Criteria for prioritizing and selecting core international crimes cases (Torkel Opsahl Academic EPublisher, 2010).

[8] Hugo Fernando Saidiza et al., Informe sobre criterios de selección y priorización en la investigación y judicialización en contextos de justicia transicional, Avocats sans frontieres Canada (2018).

[9] Richard Arens, Nuremberg and group Prosecution, 1951 Wash. U.L.Q.329 (1951).

[10] Esta selección reducida operó al principio de la transición. Más adelante, más casos han sido judicializados y se han presentado nuevas discusiones sobre priorización y selección. Ver: Mirna Goransky \& Ana Maria Luisa Pique, (The Lack of) Criteria for the Selection of Crimes Against Humanity Cases: The Case of Argentina, En Morten Bergsmo, Criteria for Prioritizing and Selecting Core International Crimes Cases, Torkel Opsahl Academic EPublisher, Oslo (2010).

[11] Acto Legislativo 01 de 2017 (reforma constitucional para la creación del Sistema Integral de Verdad, Justicia, Reparación y No Repetición). Ley 1957 de 2019 (Ley Estatutaria para la Administración de Justicia en la Jurisdicción Especial para la Paz). Ley 1922 de 2018 (ley de procedimiento de la Jurisdicción Especial para la Paz).

[12] Corte Constitucional. Sentencia C-579 de 2013. (M.P. Jorge Ignacio Pretelt Chaljub: 28 de agosto de 2013).

[13] Rodrigo Uprimny Yepes, Luz María Sánchez Duque \& Nelson Camilo Sánchez León, Justicia para la paz. Crímenes atroces, derecho a la justicia y paz negociada (Centro de Estudios de Derecho, Justicia y Sociedad, 2013); Rodrigo Uprimny Yepes \& Nelson Camilo Sánchez León, Beyond the Binary. Securing Peace and Promoting Justice after Conflict (Centro de Estudios de Derecho, Justicia y Sociedad, 2019).

[14] Louise Mallinder, Amnesty, human rights and political transitions: Bridging the peace and justice divide (Hart Publishing, 2008); Mark Freeman, Necessary evils: Amnesties and the search for justice (Cambridge University Press, 2010); Luis Miguel Gutiérrez Ramírez, La obligación internacional de investigar, juzgar y sancionar graves violaciones a los derechos humanos en contextos de justicia transicional, 16 Estudios Socio-Jurídicos, n. ${ }^{\circ}$ 2, 23-60 (2014).

[15] Mariano Gaitán, Prosecutorial discretion in the investigation and prosecution of massive human rights violations: Lessons from the Argentinian experience, 32 American University International Law Review, n. . 2, 540-568 (2018).

[16] Iván Orozco, Pronunciamiento público ante la Corte Constitucional. Notas no publicadas, en archivo de los autores (27 de mayo de 2014).

[17] Claudia López Díaz, Selección y priorización de delitos como estrategia de investigación en la justicia transicional, 42 Revista Facultad de Derecho y Ciencias Políticas, n. ${ }^{\circ}$ 117, 515-579 (2012).

[18] Como lo sostienen Bergsmo y Saffon, la selección parece inevitable en procesos de paz para terminar conflictos de alta crueldad y larga duración. Por esta razón, estos autores han sostenido que la mejor manera para garantizar los derechos de las víctimas no es negando la selección, sino definiendo los criterios sobre los cuales esta se daría de tal manera que se satisfagan en el máximo nivel posible las expectativas de verdad, justicia y reparación. Morten Bergsmo \& María Paula Saffon, Enfrentando una fila de atrocidades pasadas. ¿Cómo seleccionar y priorizar casos de crímenes internacionales 
centrales?, en Selección y priorización como estrategia de persecución en los casos de crímenes internacionales. Un estudio comparado (Kai Ambos ed., ProFis-GIZ, 2011).

[19] Marco Antonio Macana \& Luis Antonio Castro Alegría, Criterios de selección de crímenes internacionales en la justicia transicional con respecto al conflicto armado no internacional en Colombia, 23 Papel político, n. ${ }^{\circ}$ 1, 91-130 (2018).

[20] Xabier Agirre, Prosecuting the most responsable for international crimes. Dilemmas of definition and prosecutorial discretion, en Protección internacional de los derechos humanos y Estado de Derecho, Bogotá (Joaquín González ed., Grupo Editorial Ibañez, 2009).

[21] Rodrigo Uprimny Yepes, Luz María Sánchez Duque \& Nelson Camilo Sánchez León, op. cit.

[22] Fatou Besouda, Escrito de Amicus Curiae de la Fiscal de la Corte Penal Internacional sobre la Jurisdicción Especial para la $\operatorname{Paz}$ (2017).

[23] Cabe aclarar que la fiscal no hizo ninguna advertencia en términos de que tal adopción podría activar la competencia de la CPI.

[24] Comisión Interamericana de Derechos Humano (CIDH), Verdad, justicia y reparación: Cuarto informe sobre la situación de derechos humanos en Colombia, OEA/Ser.L/V/II. Doc. 49/13. 31 de diciembre de 2013, paras. 353-354.

[25] Louise Mallinder, Amnesties, human rights and political transitions: Bridging the peace and justice divide. Hart Publishing, Oxford (2008).

[26] University of Ulster's Transitional Justice Institute. Las pautas de Belfast sobre amnistía y responsabilidad (2012).

[27] International Human Rights Institute, Chicago Council on Global Affaire, Istituto Superiore Internazionale di Scienze Criminali \& Association Internationale de Droit Pénal, Los Principios de Chicago sobre Justicia Transicional (2007).

[28] Nicolás Palau van Hissenhoven, Trámite de la Ley de Justicia y Paz. Elementos para el control ciudadano al ejercicio del control político (Fundación Social, 2006); Hernando Valencia Villa, La Ley de Justicia y Paz de Colombia a la luz del Derecho Internacional de los Derechos Humanos (Centro de Investigación para la Paz [CIP-FUHEM], 2005).

[29] A este proceso se le conoció como postulación. El excombatiente que reconocía haber cometidos crímenes no amnistiables solicitaba al gobierno que lo postulara ante la Fiscalía para ingresar al sistema. Las cifras oficiales de postulados han variado con los años, pero su número aproximado está entre 1000 y 1500 postulados, de un total de más de 35.000 desmovilizados. Es decir, una fracción pequeña del número total de excombatientes desmovilizados reconocidos por el gobierno del momento.

[30] Nelson Camilo Sánchez \& Rodrigo Uprimny, El Marco Jurídico Para La Paz: ¿Cheque En Blanco O Camisa De Fuerza Para Las Negociaciones De Paz?, en Justicia Para La Paz: Crímenes Atroces, Derecho a La Justicia Y Paz Negociada (Rodrigo Uprimny Yepes, Luz María Sánchez Duque and Nelson Camilo Sánchez León eds., Centro de Estudios de Derecho, Justicia y Sociedad, Dejusticia, 2014).

[31] Corte Constitucional. Sentencia C-673 de 2005. (M. P. Clara Inés Vargas Hernández; 30 de junio de 2005).

[32] Posteriormente, el Congreso aprobó la Ley 1592 de 2012 que modificó la Ley de Justicia y Paz y se orientó a un modelo de priorización basado en la investigación de macrocasos.

[33] Nelson Camilo Sánchez y Rodrigo Uprimny, op. cit.

[34] Así, el Artículo 66 Transitorio de la Constitución establece que: “(...), el Congreso de la República, por iniciativa del Gobierno nacional, podrá mediante ley estatutaria determinar criterios de selección que permitan centrar los esfuerzos en la investigación penal de los máximos responsables de todos los delitos que adquieran la connotación de crímenes de lesa humanidad, genocidio, o crímenes de guerra cometidos de manera sistemática; (....) y autorizar la renuncia condicionada a la persecución judicial penal de todos los casos no seleccionados (....) En cualquier caso, el tratamiento penal especial mediante la aplicación de instrumentos constitucionales como los anteriores estará sujeto al cumplimiento de condiciones tales como la dejación de las armas, el reconocimiento de responsabilidad, la contribución al esclarecimiento de la verdad y a la reparación integral de las víctimas, la liberación de los secuestrados, y la desvinculación de los menores de edad reclutados ilícitamente que se encuentren en poder de los grupos armados al margen de la ley".

[35] Corte Constitucional. Sentencia C-579 de 2013 (M.P. Jorge Ignacio Pretelt Chaljub; 28 de agosto de 2013).

[36] Íd.

[37] Íd.

[38] Delegación de Paz de las FARC-EP, Sobre un Marco Jurídico fuera de contexto (2013).

[39] De hecho, algunos expertos en asuntos militares señalaron que este fue una de las razones por las cuales el proceso de desmovilización de los paramilitares terminó con distintos procesos de rearme. Para los expertos, una vez los mandos altos y medios fueron puestos en prisión, otras figuras se sintieron avalados para tomar liderazgos y efectivamente lo hicieron, sin la posibilidad de que los antiguos líderes pudieran ejercer alguna autoridad, pues estaban detenidos, y sus tropas los veían ya derrotados y sin poder.

[40] Rodrigo Uprimny Yepes, Luz María Sánchez Duque \& Nelson Camilo Sánchez León, op. cit., 102-103.

[41] Paul Seils, Propuesta de criterios de selección y priorización para la ley de Justicia y Paz en Colombia (2012); Claudia López Díaz, op. cit. 
[42] Estado de Colombia y FARC-EP. Acuerdo Final para la Terminación del Conflicto y la Construcción de una Paz Estable y Duradera (2016), punto 5, para. 32.

[43] Íd.

[44] Rodrigo Uprimny Yepes, Luz María Sánchez Duque \& Nelson Camilo Sánchez León, op. cit., 171.

[45] Estado de Colombia y FARC-EP. Acuerdo Final para la Terminación del Conflicto y la Construcción de una Paz Estable y Duradera (2016), punto 5, para. 48.

[46] Íd., punto 5, paras. 23-24.

[47] Íd., punto 5, para. 34.

[48] Íd., punto 5, para. 22.

[49] Íd., punto 5, para. 25.

[50] Íd., punto 5, paras. 40-41.

[51] Íd., punto 5, paras. 60-63.

[52] Íd., punto 5, para. 13.

[53] Íd., punto 5, para. 48.s.

[54] Íd., punto 5, para. 51.d.

[55] Íd., punto 5, para. 48.s.

[56] Íd., punto 5, para. 20.

[57] Íd., punto 5, para. 48.s.

[58] Íd., punto 5, para. 50.c.

[59] Íd., punto 5, para. 51.d.

[60] Íd., punto 5, para. 48.s.

[61] Íd., punto 5, para. 48.m.

[62] Íd., punto 5, para. 48.o.

[63] Íd., punto 5, para. 48.p.

[64] Íd., punto 5, para. 48.p.

[65] Íd., punto 5, para. 50.e.

[66] Acto Legislativo 1 de 2017, art. 1.

[67] Íd.

[68] Corte Constitucional. Sentencia C-674 de 2017. (M.P. Luis Guillermo Guerrero Pérez; 14 de noviembre de 2017).

[69] Íd.

[70] Íd.

[71] Ley 1957 de 2019.

[72] Corte Constitucional. Sentencia C-080 de 2018. (M.P. Antonio José Lizarazo Ocampo; 15 de agosto de 2018). Anexo, art. 84.c.

[73] Íd., art. 19.

[74] Íd.

[75] Íd.

[76] Corte Constitucional. Sentencia C-080 de 2018. (M.P. Antonio José Lizarazo Ocampo: 15 de agosto de 2018). Anexo, art. 38.c.

[77] Íd., art. 79.o.

[78] Íd., art. 79.t.

[79] Íd.

[80] Íd.

[81] Íd.

[82] Íd.

[83] Íd.

[84] Íd.

[85] Ley 1922 de 2018.

[86] Íd., art. 27.2.

[87] Íd., art. 71.

[88] Íd., art. 10.

[89] Íd., art. 13.5.

[90] Íd., art. 50.

[91] JEP. SRVR. Criterios y metodología de priorización de casos y situaciones en la Sala de Reconocimiento de Verdad, de Responsabilidad y de Determinación de los Hechos y Conductas. 28 de junio de 2018, párr. 1.

[92] Íd., párr. 38.

[93] Íd., párr. 25.a. 
[94] Íd., párr. 25.b.

[95] Íd., párr. 27.

[96] Íd., párr. 28.

[97] Íd., párr. 37.

[98] Íd., párr. 40.

[99] Sabine Michalowski \& Jorge Parra Norato, Los "máximos responsables" en el marco de la Jurisdicción Especial para la Paz. Documento no publicado, en archivo de los autores.

* Artículo de reflexión

\section{Licencia Creative Commons CC BY 4.0}

Cómo citar este artículo: Nelson Camilo Sánchez León \& Alejandro Jiménez Ospina, La selección y priorización de casos en la Jurisdicción Especial para la Paz, 69 Vniversitas (2020). https://doi.org/10.1114 4/Javeriana.vj69.spcj 